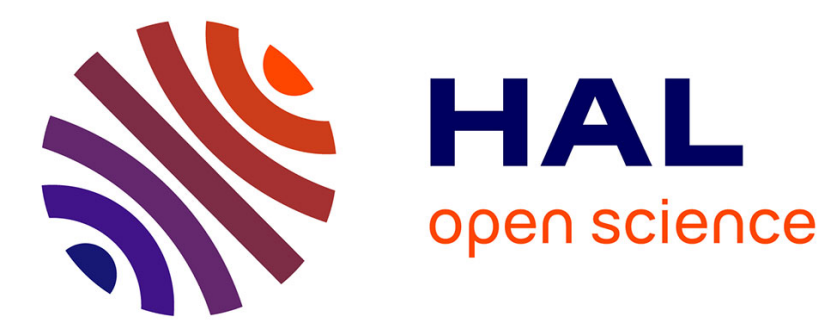

\title{
Sustainable supply chain network design: An optimization-oriented review
}

Majid Eskandarpour, Pierre Dejax, Joe Miemczyk, Olivier Péton

\section{To cite this version:}

Majid Eskandarpour, Pierre Dejax, Joe Miemczyk, Olivier Péton. Sustainable supply chain network design: An optimization-oriented review. Omega, 2015, 54, pp.11-32. 10.1016/j.omega.2015.01.006 . hal-01154605

\section{HAL Id: hal-01154605 \\ https://hal.science/hal-01154605}

Submitted on 28 May 2015

HAL is a multi-disciplinary open access archive for the deposit and dissemination of scientific research documents, whether they are published or not. The documents may come from teaching and research institutions in France or abroad, or from public or private research centers.
L'archive ouverte pluridisciplinaire HAL, est destinée au dépôt et à la diffusion de documents scientifiques de niveau recherche, publiés ou non, émanant des établissements d'enseignement et de recherche français ou étrangers, des laboratoires publics ou privés. 


\title{
Sustainable supply chain network design: an optimization-oriented review
}

\author{
Majid Eskandarpour ${ }^{1} \quad$ Pierre Dejax $^{1} \quad$ Joe Miemczyk $^{2,3} \quad$ Olivier Péton $^{1}$ \\ ${ }^{1}$ Ecole des Mines de Nantes, IRCCyN UMR CNRS 6597 \\ (Institut de Recherche en Communications et Cybernétique de Nantes), Nantes, France \\ email: \{majid.eskandarpour, pierre.dejax, olivier.peton\}@mines-nantes.fr \\ 2 Audencia Nantes School of Management, 44312 Nantes, France \\ 3 Aix Marseille Université, CRET-LOG EA 881, 13625, Aix en Provence, France \\ email: jmiemczyk@audencia.com
}

January 2015

\section{Introduction}

Supply chain management has become a strategic issue for any company looking to meet targets in terms of economic competitiveness, time and quality of service especially in an economic environment characterized by the globalization of trade and the acceleration of industrial cycles. The trade press is replete with examples of logistics network configuration, re-configuration, re-organization, mergers, outsourcing, and so on. These developments have been influenced by successive trends in the economy and society resulting from computerization, increased complexity of trade flows, increased competition and certainly not least, sustainable development. Thus the strategic design and planning of logistics networks is a topic that is becoming more important for businesses and researchers alike. Supply chain network design is at the intersection of disciplines such as management, strategy, logistics, operations research and as such, there is a significant challenge to researchers to consolidate and synthesize the research in this field, which leads to the focus of this paper.

Supply Chain Management (SCM) spans all movements and storage of raw materials, work-in-process inventory, and finished goods from the point-of-origin to the point-of-consumption [Simchi-Levi et al., 2004]. It encompasses three decision levels: strategic, tactical and operational. In particular, at the strategic level, Supply Chain Design comprises the decisions regarding the number and location of production and storage facilities, the amount of capacity at each facility, the conciliation of market demand, and decisions on supplier selection from a total cost perspective [Chopra and Meindl, 2004]. From an operations research point of view, Supply Chain Network Design (SCND) is the discipline used to determine the optimal location and size of facilities and the flow through the facilities [Autry et al., 2013]. As recalled in Zanjirani Farahani et al. [2014], "there are many models in the SCND literature. Different decisions are made in the SCND and perhaps the most critical one is locating the facilities in different tiers of the supply chain".

Fifty years ago, the seminal paper by Hakimi [1964] generalized the original Weber problem [Weber and Peik, 1909] from a single facility location problem to a multiple facility location problem. This publication marked a revival of the facility location problem, which has become one of the standard problems in the operations research community. Recent years have been characterized by a rapid enrichment of these 
mathematical model solutions. Rich models now handle multiple levels in the logistics network, multiple periods, products, technologies, transportation modes and types of facilities. They integrate capacity constraints, tactical decisions and complex product flows. Thus, Supply Chain Network Design (SCND) can be considered as the meeting point of the academic facility location problem and the real-life SCND problem.

As already mentioned, among the major trends in SCM, the principles of sustainable development have spread across the scientific literature. Current research mainly consists of assessing SCM policies according to a triple bottom line including economic aspects, environmental performance and social responsibility. Sustainable SCM has been the subject of numerous survey papers in both qualitative and quantitative disciplines. A number of review papers have been published in recent years, which relate to major trends in Supply Chain Management and investigate and suggest research opportunities. Importantly, research in sustainable SCND has hardly been reviewed at all. However, the integration of sustainability into SCND may change the locations of production facilities and inventories (see for example Figures 12-14 in You and Wang [2011]) and therefore have a significant impact on the environment and society. The goal of this paper is to bridge this gap.

More precisely, our objective is to review SCND problems that include a clear assessment of at least two of the three dimensions of sustainable development: economic aspects, environmental performance and social responsibility. We review papers containing mathematical models (linear and nonlinear programs with integer or mixed-integer variables) with binary decision variables modeling the selection of candidate facilities.

Our research questions can be briefly stated as follows: (i) which environmental and social criteria are considered in sustainable SCND research? (ii) how are they integrated into mathematical models? (iii) which optimization methods and tools are used? (iv) which real-life applications of sustainable SCND are described in the scientific literature?

Section 2 describes the methodology adopted for the collection of research papers and compares our work with existing reviews on related topics. SCND problems with environmental and social aspects are investigated in sections 3 and 4, respectively. In section 3, we give a special focus on LCA-based methods and review the scope of the environmental assessment, the environmental criteria used and the metrics chosen to evaluate these criteria. The section 5 reviews the mathematical models. We used 3 main classification dimensions: mono-objective versus multi-objective models, linear vs non linear, deterministic vs stochastic. The solution methods are described in section 6 , which lists the use of solvers, other exact methods and heuristic or metaheuristic approaches. We devote section 7 to the description of case studies and real-life applications of sustainable SCND. The references are classified according to the type of economic activity and the nature of the data. Finally, in section 8 we conclude and suggest a number of future research directions.

\section{Review methodology}

\subsection{Delimitations and search for literature}

A comprehensive search of related research from 1990 to 2014 was applied to produce a synthesis of peer-reviewed literature. The start of the time period was chosen such that the Brundtland Report of the World Commission on Environment and Development [Burton, 1987] served as a starting point, in a similar way to Seuring and Müller [2008] and Chen et al. [2014].

We searched papers published in international peer-reviewed journals from the main electronic bibliographical sources (Scopus, Web of Science) using keywords such as sustainable development, green, environmental or social along with classic keywords such as supply chain, network design or facility location in the titles or the topics covered. We use back-tracking to find earlier relevant sources, and forward-tracking in Web of Science to find literature that are referring to the central sources. We also 
looked for recent surveys in related domains in order to find additional sources including a few conference papers.

From the collected material, we filtered the papers according to the following rules: (i) the papers must be written in English language, (ii) they include decision variables modeling the location or selection of candidate facilities, (iii) the measure of environmental or social impact is explicit either in the objective function or in the constraints of the model.

From the second rule, we excluded a large number of articles dealing with the routing of product flows in an already defined network. This is the case, for example, in the paper by Ramos et al. [2014], in which the authors present depot selection as an extension of their work. The third rule enabled us to filter many papers in the field of reverse logistics and management of undesirable facilities. Reverse logistics and closed-loop supply chain have become a major area of supply chain management. Several surveys have been published in the last fifteen years (see for example the surveys by Fleischmann et al. [1997], Dekker et al. [2004], Bostel et al. [2005], Pokharel and Mutha [2009] or the special issues [Guide and Van Wassenhove, 2006a,b]). Clearly, the goal of reverse or closed-loop supply chain is closely related to that of sustainable supply chain management. However, as explained in Srivastava [2008] (Figure 4), the main optimization often relies on a single economic objective. Environmental and social dimensions are generally not explicitly assessed, but the resolution of these problems evidently contributes to designing sustainable supply chain networks.

Undesirable facilities are those facilities that have adverse effects on people or the environment. They generate some form of pollution, nuisance, potential health hazard, or danger to nearby residents; they also may harm nearby ecosystems [Melachrinoudis, 2011]. Thus, the modeling of SCND problems that include undesirable facilities often implicitly include environmental or social aspects.

On that basis, 87 papers were identified. In the following, they are denoted as reference papers and listed in a separate category in the reference list in the end of this review.

\subsection{Position in the literature}

As many review papers have been written in neighboring domains, we needed to check whether the scope of the present paper was not already covered by the existing literature. Table 1 summarizes the reviews published in related areas. The symbol $\bullet$ in columns 2 means that the corresponding paper considers facility location as a main topic. The symbols $\bigcirc$ and $\times$ mean that facility location is one topic among others or is not studied in the paper. The symbols have the same meaning in further tables.

We can classify the review papers in two categories. The first category gathers papers dealing with Supply Chain Management in general. In these papers, facility location is either not studied or is only one feature among many others. For example, Brandenburg et al. [2014] mention network design as one out of 13 application areas. They mention 13 papers in this area, all except one being published between 2010 and 2013. Seuring [2013] indicates that more than 300 articles have been published in the last 15 years on the topic of green or sustainable (forward) supply chains, only 36 articles of which apply quantitative models. Note that the review by Barbosa Póvoa [Barbosa-Póvoa, 2014] concerns supply chain management, but with a strong emphasis on supply chain network design. The second category regroups review papers on SCND. Only 5 of them deal with sustainability.

Table 2 details the content of the reviews which could potentially cover the sections 3,5 and 6 of our work: LCA based approaches (column 4), optimization models (column 5) and optimization methods (column 6). The last column reports the number of references also mentioned in the present review.

Several reviews are dedicated to one activity: chemical and process industries [Barbosa-Póvoa, 2014, Nikolopoulou and Ierapetritou, 2012], biomass-to-energy [De Meyer et al., 2014, Yue et al., 2014].

Boukherroub et al. [2012] focus on multi-criteria decision making models for supply chain design. They point 42 papers with environmental or social concern, and 43 papers with facility location decisions, 12 of them having both characteristics. The broad review by Dekker et al. [2012] contains one section on 
Table 1: Existing reviews in related areas. $\mathrm{RL}=$ Reverse Logistics, $\mathrm{CL}=$ Closed-Loop

\begin{tabular}{|c|c|c|c|}
\hline Article & $\begin{array}{l}\text { Facility } \\
\text { location }\end{array}$ & Sustainability & $\begin{array}{l}\text { Scope or } \\
\text { special focus }\end{array}$ \\
\hline \multicolumn{4}{|l|}{ Supply Chain Management } \\
\hline Srivastava [2007] & 0 & • & Green SCM, RL, CL \\
\hline Awudu and Zhang [2012] & 0 & • & Biofuel SCM, uncertainty \\
\hline Dekker et al. [2012] & 0 & ? & Green logistics \\
\hline Soysal et al. [2012] & 0 & • & Quantitative models, food logistics \\
\hline Nikolopoulou and Ierapetritou [2012] & 0 & $\bullet$ & Chemistry \\
\hline Boukherroub et al. [2012] & 0 & • & Multi-criteria models \\
\hline Brandenburg et al. [2014] & 0 & 0 & OR models and methods \\
\hline Masoumik et al. [2014] & 0 & $\bullet$ & $\mathrm{RL}, \mathrm{CL}$ \\
\hline Barbosa-Póvoa [2014] & 0 & 0 & Chemical process \\
\hline Yue et al. [2014] & 0 & 0 & Biomass-for-bioenergy \\
\hline Arioglu Salmona et al. [2010] & $x$ & • & \\
\hline Sarkis et al. [2011] & $x$ & e & Green SCM \\
\hline Ashby et al. [2012] & $x$ & 0 & \\
\hline Miemczyk et al. [2012] & $\times$ & 0 & Purchasing \\
\hline Seman et al. [2012] & $x$ & • & Green SCM \\
\hline Zailani et al. [2012] & $x$ & 0 & Malaysia \\
\hline Beske et al. [2013] & $x$ & $\bullet$ & Dynamic capabilities, food industry \\
\hline Seuring $[2013]$ & $x$ & $\bullet$ & Forward supply chain \\
\hline Yusuf et al. [2013] & $x$ & e & UK oil and gas supply chains \\
\hline Ashby et al. [2012] & $x$ & • & \\
\hline Seuring and Müller [2008] & $x$ & 0 & \\
\hline Gupta and Palsule-Desai [2011] & $x$ & 0 & \\
\hline Johnsen et al. [2012] & $x$ & $\bullet$ & \\
\hline \multicolumn{4}{|l|}{ Supply Chain Network Design } \\
\hline Terouhid et al. [2012] & e & e & Socially responsible location \\
\hline Chen et al. [2014] & $\bullet$ & 0 & Manufacturing \\
\hline Devika et al. [2014] & • & 0 & Forward, RL,CL \\
\hline Zanjirani Farahani et al. [2014] & 0 & 0 & Competitive SCND \\
\hline Beamon [1998] & • & $x$ & \\
\hline Owen and Daskin [1998] & 0 & $\times$ & \\
\hline Daskin et al. [2005] & 0 & $\times$ & \\
\hline M. and G. [2005] & 0 & $x$ & \\
\hline Sahin and Süral [2007] & 0 & $x$ & \\
\hline Akçalı et al. [2009] & • & $x$ & $\mathrm{RL}, \mathrm{CL}$ \\
\hline Melo et al. [2009] & - & $x$ & \\
\hline Aras et al. [2010] & • & $x$ & $\mathrm{RL}, \mathrm{CL}$ \\
\hline Pati et al. [2013] & $\bullet$ & $x$ & RL,CL, single objective \\
\hline Hassini et al. [2012] & 0 & • & Metrics \\
\hline De Meyer et al. [2014] & 0 & 0 & Biomass-to-bioenergy \\
\hline
\end{tabular}


Table 2: Existing reviews in related areas

\begin{tabular}{|c|c|c|c|c|c|c|}
\hline Article & $\begin{array}{l}\text { Facility } \\
\text { location }\end{array}$ & Sustainability & LCA & $\begin{array}{l}\text { Optimization } \\
\text { models }\end{array}$ & $\begin{array}{l}\text { Optimization } \\
\text { methods }\end{array}$ & $\begin{array}{l}\# \text { of shared } \\
\text { references }\end{array}$ \\
\hline Nikolopoulou and Ierapetritou [2012] & O & $\bullet$ & 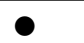 & 0 & 0 & 12 \\
\hline Boukherroub et al. [2012] & 0 & $\bullet$ & 0 & $\bullet$ & $\bullet$ & 12 \\
\hline Dekker et al. [2012] & 0 & - & $x$ & 0 & $x$ & 7 \\
\hline De Meyer et al. [2014] & 0 & $\bullet$ & $x$ & - & $\bullet$ & 5 \\
\hline Barbosa-Póvoa [2014] & 0 & 0 & $x$ & 0 & 0 & 7 \\
\hline Yue et al. [2014] & 0 & 0 & 0 & 0 & 0 & 12 \\
\hline Terouhid et al. [2012] & 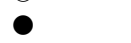 & $\bullet$ & $x$ & $x$ & $x$ & 1 \\
\hline Chen et al. [2014] & 0 & $\bullet$ & $x$ & $x$ & $x$ & 1 \\
\hline Devika et al. [2014] & 0 & 0 & $x$ & - & - & 10 \\
\hline Zanjirani Farahani et al. [2014] & • & 0 & $x$ & $x$ & $x$ & 9 \\
\hline
\end{tabular}

facility location (7 shared papers).

Terouhid et al. [2012] and Chen et al. [2014] propose a framework for classifying the sustainability characteristics. They study the factors affecting location decisions, but these reviews do not review the quantitative models and methods. Devika et al. [2014] is a research paper including a section with a review of the literature.

We conclude that none of these reviews addresses the subject of OR models and methods for sustainable supply chain network design.

\subsection{Distribution across the time period and main journals}

Figure 2.3 displays the yearly distribution of the reference papers. A remarkable fact is that almost $90 \%$ of these papers have been published since 2008, making it clear that sustainable SCND has been receiving growing attention.

The reference papers can be found in 41 distinct journals, only 17 of them having published more than 1 paper. Figure 2.3 shows the distribution of the reference papers in these 17 journals, which represent $72 \%$ of the reference papers. The high number of papers in Computers and Chemical Engineering and Industrial $\&$ Engineering Chemistry Research underlines the importance of sustainability in chemical and process industry. Many papers are published in journals which focus on sustainability or on one field of application. For example, Resources, Conservation and Recycling and Waste Management fall into this category. On the other hand, the papers published in Industrial Engineering and Operational Research journals are spread out in a large variety of journals.

\subsection{The 3 dimensions of sustainable development}

The reference papers do not all address the 3 dimensions of sustainable development: economic aspects, environmental performance and social responsibility. Figure 2.4 shows their distribution with respect to these dimensions. This distribution is consistent with that already observed in other reviews, such as Chen et al. [2014]. The paucity of papers including social aspects has been already observed by many preceding reviews, and this is even more striking in quantitative models.

\section{Environmental Supply Chain Network Design}

Network design mathematical models traditionally aimed at minimizing cost or maximizing profit, with very little consideration of environmental objectives and constraints. The increasing importance of en- 


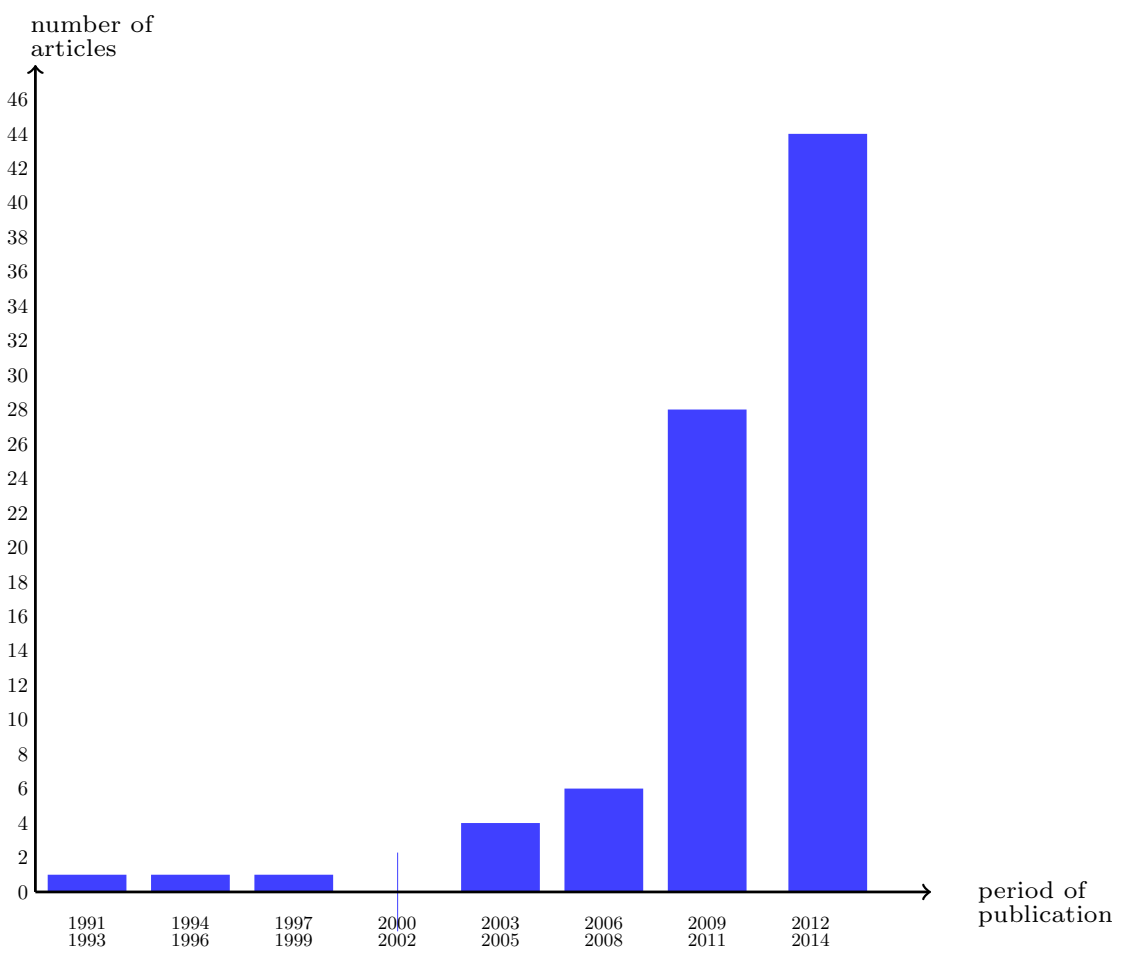

Figure 1: Time distribution of reference papers

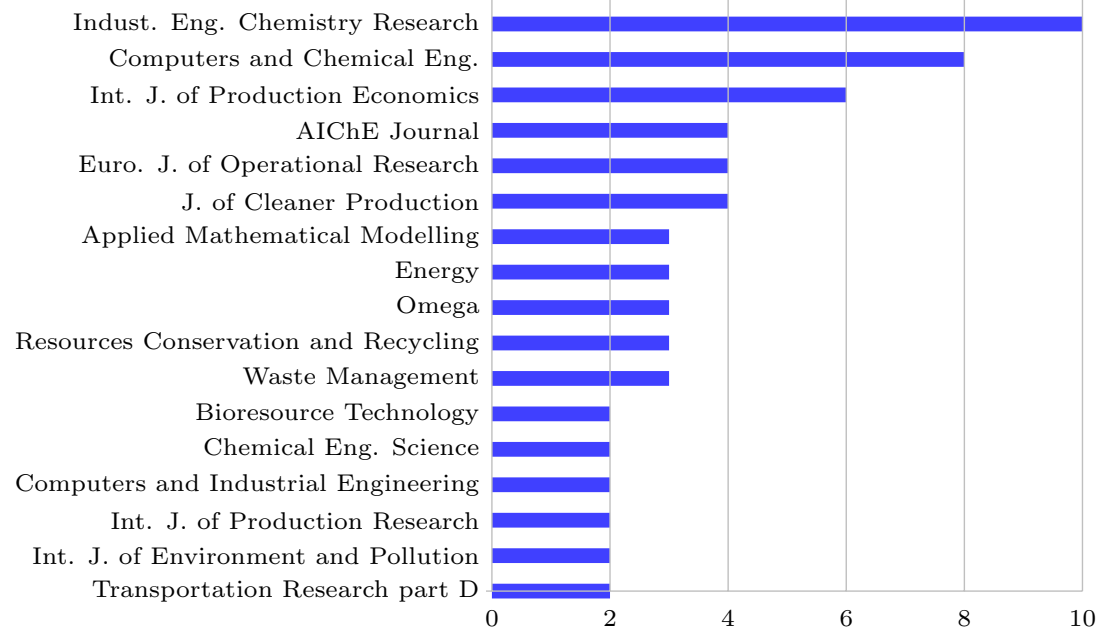

Figure 2: Distribution of reference papers by journal 


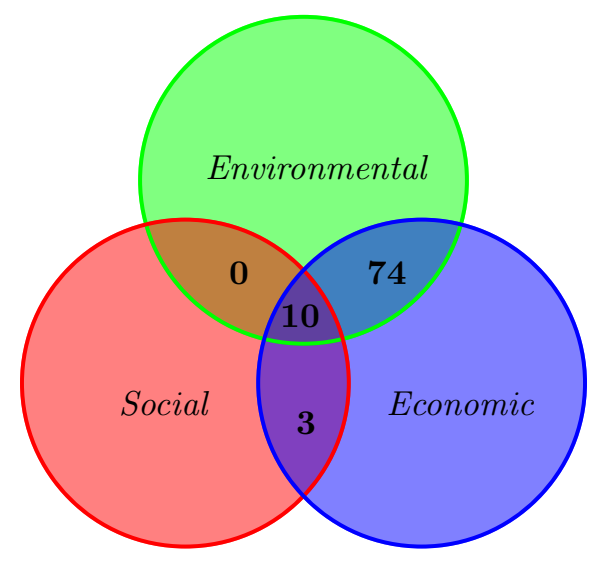

Figure 3: Distribution of reference papers with respect to the 3 sustainability dimensions

vironmental issues has prompted decision-makers to incorporate environmental factors fully into the decision process [Ilgin and Gupta, 2010], giving birth to Environmental Supply Chain Network Design (ESCND). In other words, ESCND generalizes SCND by incorporating environmental factors, which may concern facilities, transportation modes, processes, product design, technological choices, etc. As shown for example in the case study in You and Wang [2011], the optimal solutions of pure economic, environmental or intermediate models differ a lot.

This raises several questions that should be clarified when designing supply chains. Which environmental factors should be considered? How can they be quantified? How can they be integrated into mathematical models and optimization methods?

Table 4 in Brandenburg et al. [2014] or Table 1 in Seuring [2013] show that many possible way to model environmental decision making: Life Cycle Assessment (LCA), reasoning maps, Analytic Hierarchy Process (AHP), Analytic Network Process (ANP), Data Envelopment Analysis (DEA), equilibrium models, simulation, etc. However, LCA is the most commonly used technique and it is particularly convenient to integrate its output in optimization models. Moreover, this technique is a general framework for a holistic assessment of a supply chain from extraction of raw material to disposal of end products. Thus, in subsection 3.1, we focus on papers which assess supply chain environmental impact through an LCA approach. Some reference papers adopt a full LCA approach and others only calculate one or a few LCA indicators which are further integrated into optimization models. These two approaches will be discussed in sections 3.1.2. Subsection 3.2 concerns papers that do not adopt an LCA approach. They rather propose partial assessment of environmental factors, focused on one or several dominating aspects of the application considered, for example emissions caused by transportation or facilities.

\subsection{LCA based models}

LCA assesses environmental impacts associated with all stages of a product life-cycle from raw material extraction to final disposal or recycling [ISO, 2006]. It compiles and evaluates inputs, outputs and potential environmental impacts of a product system throughout its manufacturing process (see the reviews by Azapagic [1999] and Pieragostini et al. [2012]), its life-cycle and all related supply chain decisions.

The Figure 4 represents the four main steps of LCA as defined by the ISO 14040 and 14044 standards [ISO, 2006].

1. Goal and scope definition sets out main objectives of the study, defines functional units considered 


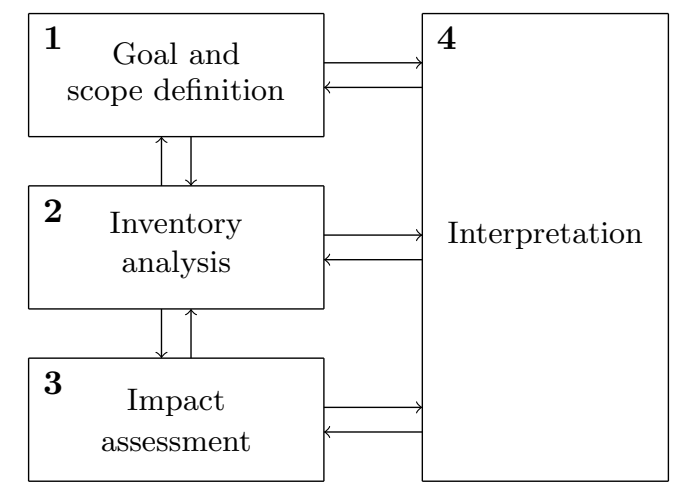

Figure 4: Conceptual framework of LCA [ISO, 2006]

and boundaries of the system.

2. Inventory analysis is inventory of all flows from and to nature for a product system. All emissions (in air, water and soil), extractions and land use are listed and quantified.

3. Impact assessment measures environmental impact of all emissions listed in the preceding step.

4. Results interpretation consists in analyzing and interpreting results of each of the three preceding steps. The outcome of the interpretation phase is a set of conclusions and recommendations for the study.

We found 39 papers that integrate principles of LCA into their supply chain network design models. Among the four LCA steps, we review the goal and scope definition and the impact assessment steps. The inventory analysis is an important intermediate step but it is directly related to supply chain decisions. The mathematical models resulting from the preceding steps are considered by several authors as a part of the interpretation step.

\subsubsection{Scope definition}

To determine boundaries of the supply chain is the first critical decision in LCA.

The cradle-to-grave scope assumes a comprehensive assessment of environmental impact through the whole supply chain from raw material to materials processing, manufacture, distribution, use, repair and maintenance, disposal and recycling. This category regroups 12 papers. In the context of fuel supply chains, cradle-to-grave is called well-to-wheel (WTW). For example, Elia et al. [2011] provide an analysis for hybrid coal, biomass, and natural gas to liquid (CBGTL) plants. The supply chain described includes both cultivation of biomass and coal and natural gas mining, followed by industrial and logistics operations. In the context of biomass supply chains, cradle-to-grave is called field-to-wheel (FTW). This is applied to cellulosic ethanol [You et al., 2012], sugar cane to ethanol [Mele et al., 2009] or to a general "biomass-to-liquid" supply chain [You and Wang, 2011].

The cradle-to-gate scope concerns all steps from extraction to the factory gate (23 papers). This scope is frequent for B2B companies having multiple customers. In fuel supply chains, this LCA scope is called well-to-tank in order to distinguish the GHG emitted during fuel production from those emitted by the vehicle operations. It is called field-to-tank in biomass supply chains.

Gate-to-gate (3 papers) generally concerns companies in intermediate echelons of a supply chain, which manufacture or transform and deliver goods to their customers without extracting raw materials 

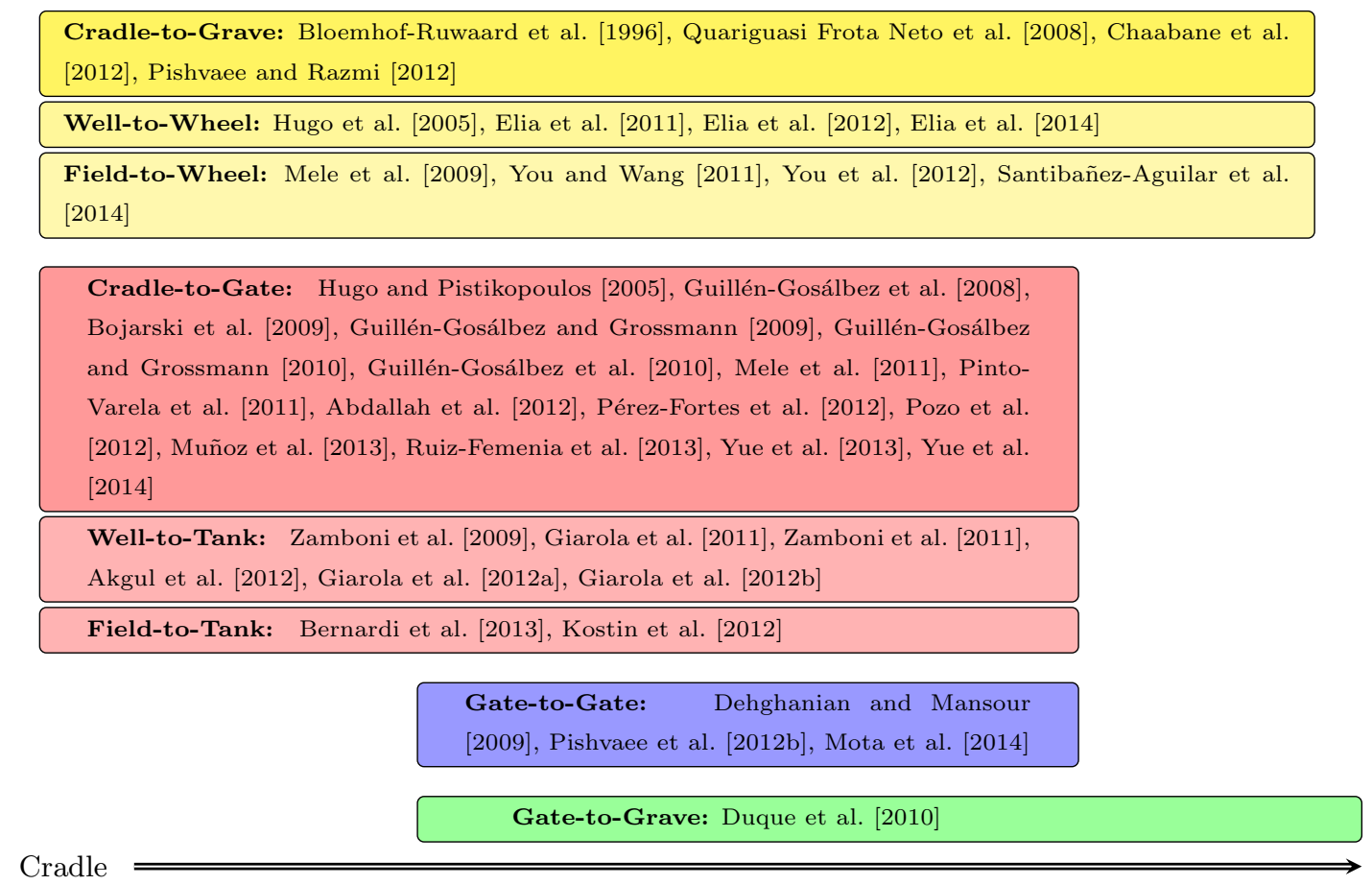

Grave

Figure 5: LCA scopes

or playing any role in disposal of end-of-life products. This scope is also used in transformation of endof-life products which are re-used in the same or another supply chain. For example, Dehghanian and Mansour [2009] study a recovery network for scrap tires which can be used as a substitute for fuel in cement plants.

Gate-to-Grave (1 paper) focuses on the last steps of a supply chain, from factory gate to product disposal. This scope is convenient in the study of waste supply chains or reverse logistics activities.

\subsubsection{Life-Cycle Impact Assessment}

The goal of life-cycle impact assessment (LCIA) is to express the complex output of inventory analysis into a few environmental areas of interest. Mid-point oriented LCIA methods cover various impact categories such as greenhouse effect (or climate change), natural resource depletion, stratospheric ozone depletion, acidification, eutrophication, human toxicity, aquatic toxicity, etc. Damage-oriented methods (or endpoint methods) aggregate mid-point categories into fewer categories of damage: damage to human health, ecosystem health or damage to resources. There exist several LCIA methodologies, which include different midpoint and endpoint categories.

In the mathematical models described in the reference papers, the environmental assessment can be based either on midpoint or endpoint categories. Models can include exhaustive LCA or only a small subset of pertinent impact categories. We call the latter approach an LCA-based approach.

\section{LCIA methods}

The Table 3 lists papers based on endpoint methodologies. Three methods are described in reference papers: Eco-Indicator 99 (EI-99), Impact 2002+ and ReCiPe. 
Table 3: LCIA methods

\begin{tabular}{ll}
\hline Method & Articles \\
\hline Eco-Indicator 99 (EI-99) & Pishvaee and Razmi [2012], Hugo and Pistikopoulos [2005], Guillén- \\
& Gosálbez et al. [2008], Guillén-Gosálbez and Grossmann [2009], Duque \\
& et al. [2010], Guillén-Gosálbez and Grossmann [2010], Mele et al. \\
& [2011], Abdallah et al. [2012], Pozo et al. [2012], Dehghanian and Man- \\
& sour [2009], Chaabane et al. [2012], Kostin et al. [2012],Santibañez- \\
& Aguilar et al. [2014],Yue et al. [2013] \\
\hline IMPACT 2002+ & Bojarski et al. [2009], Pérez-Fortes et al. [2012], Muñoz et al. [2013] \\
\hline CML92 & Bloemhof-Ruwaard et al. [1996] \\
\hline ReCiPe & Mota et al. [2014] \\
\hline
\end{tabular}

Eco-indicator 99 [Goedkoop and Spriensma, 2000] gathers 11 impact categories into three damage categories (human health, ecosystem quality and resources). The overall environmental impact is finally measured as a single metric. EI-99 is chosen in 15 papers, mainly with a cradle-to-gate scope.

Depending of the industrial activity, some impact categories can be omitted. For example, in the context of chemical supply chain, Hugo and Pistikopoulos [2005] use the 10 most relevant impact indicators.

IMPACT 2002+ [Jolliet et al., 2003] has 14 midpoint indicators and 4 categories of damage: human health, quality of ecosystems, climate change and resource depletion. It is used in 3 papers with a cradleto-gate scope. In these papers, an overall environmental objective is the sum of all endpoint damages for each facility in the supply chain.

CML92 is used in Bloemhof-Ruwaard et al. [1996] with seven impact categories. ReCiPe [Goedkoop et al., 2009] has 18 midpoint categories combined into 3 endpoint damage categories (human health, ecosystems, resource surplus cost). This method also results in one single score.

\section{Impact categories}

The score provided by Eco-Indicator 99 or ReCipe can be easily incorporated into optimization models as an environmental objective function. However, although they use this approach, Pishvaee and Razmi [2012] claim that LCA process is costly, time consuming and needs expertise in environmental management. Several authors do not lead an exhaustive LCIA approach and only borrow one or a few impact categories which are directly integrated into their mathematical models. The papers that adopt this approach are listed in Table 4.

Table 4: Impact categories and indicators

\begin{tabular}{ll}
\hline Impact & Articles \\
\hline Climate Change & Hugo et al. [2005], Quariguasi Frota Neto et al. [2008], Zamboni et al. \\
& [2009], Elia et al. [2011], Giarola et al. [2011], Mele et al. [2011], You \\
& and Wang [2011], Zamboni et al. [2011], Akgul et al. [2012], Chaabane \\
& et al. [2012], Elia et al. [2012], Elia et al. [2012], Giarola et al. [2012a], \\
& Giarola et al. [2012b], Kostin et al. [2012], Pishnaee et al. [2012b], You \\
& et al. [2012], Bernardi et al. [2013], Ruiz-Femenia et al. [2013], Elia \\
& et al. [2014], Yue et al. [2014] \\
\hline Biochemical Oxygen Demand $\left(B O D_{20}\right)$ & Mele et al. [2009] \\
\hline Damage to human health & Guillén-Gosálbez et al. [2010], Pinto-Varela et al. [2011], Kostin et al. \\
& {$[2012]$,} \\
\hline Water footprint & Bernardi et al. [2013] \\
\hline
\end{tabular}


Climate change is often quantified by the Global Warming Potential (GWP) indicator [IPCC, 2007]. It is captured by inventorying $\mathrm{CO}_{2}, \mathrm{CH}_{4}, \mathrm{~N}_{2} \mathrm{O}$ emissions and regrouping them in a single indicator expressed as $\mathrm{CO}_{2}$-equivalent emissions during a predefined period, typically 100 years. GWP is mainly used with cradle-to-grave, well-to-wheel, field-to-wheel and well-to-tank scopes.

It is often used as a single indicator of environmental impact or is completed with some application dependent indicators: Bernardi et al. [2013] consider GWP and water footprint, which indicates the amount of freshwater consumed or polluted during the whole production process of a commodity.

Mele et al. [2009] measure environmental performance with biochemical oxygen demand $\left(B O D_{20}\right)$, because of its importance as an indicator of pollution of watercourses.

There can be two reasons for resorting to partial LCIA approach instead of exhaustive LCIA: simplifying calculation or focusing on impacts which are most relevant for the application considered. GuillénGosálbez et al. [2010] explore the environmental benefits of adopting a hydrogen economy, in terms of overall contribution to climate change. For this reason, instead of calculating the EI-99 itself, they focus on only one of its impact categories: damage to human health caused by climate change. Pinto-Varela et al. [2011] calculate a partial EI-99 by only considering damage to human health caused by electricity and diesel consumption. Other authors choose to consider individual impact indicator to complement one LCIA score. Kostin et al. [2012] consider three impact categories from the EI-99 (damage to human health, damage to eco-system quality, damage to resource), the EI-99 itself, and the GWP. Mele et al. [2011] consider the EI-99 and the GWP.

\subsection{Partial assessment of environmental factors}

For various reasons, implementing a methodology such as LCA is not always possible. Awareness of environmental concerns in companies is generally gradual, so that assessing only a subset of environmental factors can be viewed as an intermediate step towards full integration. Partial assessment of environmental factors also makes sense when obtaining environmental data and modeling the whole supply chain is too difficult. This section has a structure similar to that of the preceding section. We first review the scope chosen for integrating environmental concerns, i.e. which activity in the supply chain is concerned. Then, we list the performance measures used in each paper.

\subsubsection{Scope}

The easiest way to partially assess environmental factors has been to enrich traditional SCND models with one or a number of environmental objectives, constraints or parameters. This keeps the focus on logistics operations in the supply chain, while integrating new concerns into the decision process. For example, knowing that transport and industrial facilities account for $22 \%$ and $20 \%$ of global $\mathrm{CO}_{2}$ emissions respectively [OECD/IEA, 2012], several SCND models integrate $\mathrm{CO}_{2}$ emissions due to transport or facilities.

Table 5 list three categories in which environmental criteria are most often incorporated: facilities, transport and product related criteria. Next paragraphs detail the content of this table.

\section{- Facilities}

Since facility location is a central decision in SCND models, integrating environmental impact of facilities into mathematical models seems to be natural. This impact is considered in 28 of the papers in Table 5, but surprisingly enough only 6 of them measure the GHG emissions due to facilities. The most classic metric to assess the environmental impact of facilities is energy consumption, which can depend on sizing decisions and technological choices. The models by Amin and Zhang [2013], Caruso et al. [1993], Costi et al. [2004], Galante et al. [2010], Lam et al. [2013], Papapostolou et al. [2011], Pishvaee et al. [2012a] and Wang et al. [2011] include the choice between 
Table 5: Scope used for partial assessment of environmental impact

\begin{tabular}{|c|c|c|c|}
\hline Article & Facilities & Transport & Product \\
\hline $\begin{array}{l}\text { Caruso et al. [1993] } \\
\text { Berger et al. [1999] } \\
\text { Pati et al. [2008] } \\
\text { Corsano et al. [2011] } \\
\text { Erkut et al. [2008] } \\
\text { Lira-Barragán et al. [2011] } \\
\text { Pishvaee et al. [2012a] } \\
\text { Eskandarpour et al. [2013] } \\
\text { Costi et al. [2004] } \\
\text { Minciardi et al. [2008] } \\
\text { Alçada-Almeida et al. [2009] } \\
\text { Saffar et al. [2015] } \\
\text { Pourmohammadi et al. [2008] } \\
\text { Galante et al. [2010] } \\
\text { Elhedhli and Merrick [2012] } \\
\text { Mallidis et al. [2012] } \\
\text { Bouzembrak et al. [2013] } \\
\text { Sadrnia et al. [2013] } \\
\text { Xifeng et al. [2013] } \\
\text { Zhang et al. [2013] } \\
\text { Saffar et al. [2014] } \\
\text { Harraz and Galal [2011] }\end{array}$ & $\begin{array}{l}0 \\
0 \\
0 \\
0 \\
0 \\
0 \\
0 \\
0 \\
0 \\
0 \\
0 \\
0\end{array}$ & $\begin{array}{l}0 \\
0 \\
0 \\
0 \\
0 \\
0 \\
0 \\
0 \\
0 \\
0\end{array}$ & 0 \\
\hline $\begin{array}{l}\text { Ramudhin et al. [2010] } \\
\text { Chaabane et al. [2011] } \\
\text { Harris et al. [2011] } \\
\text { Liu et al. [2011] } \\
\text { Tuzkaya et al. [2011] } \\
\text { Wang et al. [2011] } \\
\text { Jamshidi et al. [2012] } \\
\text { Kannan et al. [2012] } \\
\text { Kanzian et al. [2013] } \\
\text { Lam et al. [2013] } \\
\text { Govindan et al. [2013] } \\
\text { Devika et al. [2014] } \\
\text { Marufuzzaman et al. [2014] } \\
\text { Mohammadi et al. [2014] } \\
\text { Papapostolou et al. [2011] } \\
\text { Amin and Zhang [2013] }\end{array}$ & $\begin{array}{l}0 \\
0 \\
0 \\
0 \\
0 \\
0 \\
0 \\
0 \\
0 \\
0 \\
0 \\
0 \\
0 \\
0 \\
0 \\
0\end{array}$ & $\begin{array}{l}0 \\
0 \\
0 \\
0 \\
0 \\
0 \\
0 \\
0 \\
0 \\
0 \\
0 \\
0 \\
0 \\
0 \\
0\end{array}$ & $\stackrel{\bullet}{\bullet}$ \\
\hline $\begin{array}{l}\text { Krikke et al. [2003] } \\
\text { Krikke [2011] } \\
\text { Abdallah et al. [2013] } \\
\text { Diabat et al. [2013] } \\
\text { Baud-Lavigne et al. [2014] }\end{array}$ & $\begin{array}{l}\bullet \\
\bullet \\
\bullet \\
\bullet\end{array}$ & $\begin{array}{l}0 \\
\bullet \\
\bullet \\
\bullet \\
\bullet\end{array}$ & $\begin{array}{l}0 \\
0 \\
0 \\
0 \\
0 \\
0\end{array}$ \\
\hline
\end{tabular}


competing technologies as decision variables. Pishvaee et al. [2012a] integrate the average amount of waste generated with each technology in their environmental and social objective function. Other measures include the number of obnoxious facilities installed [Eskandarpour et al., 2013] (which is influenced by technological choices) or the risk placed on the nearby population [Alçada-Almeida et al., 2009].

\section{- Transport}

One of the easiest ways to incorporate environmental criteria into pure economic models is to calculate emissions of GHG and particulates due to transport. Tools for calculating and converting emissions into a single $\mathrm{CO}_{2}$ equivalent measurement can be provided by national or regional organizations, such as the Mobile6 software used by Elhedhli and Merrick [2012] for heavy duty diesel vehicles.

Some models integrate selection of transportation modes into strategic network design decisions. In these models, transportation modes generally compete on cost, environmental impact and capacity. The choice between transportation modes can also be determined by loading/unloading conditions, frequency, minimum lot-size etc.

Since SCND models generally consider aggregated data, operational characteristics such as vehicle speed and daily variations are mostly ignored. We did not find any reference considering more global assessment of transportation, such as impact of vehicles on road network.

\section{- Process and product design}

Decisions concerning product flows and design can also be fully integrated into environmental SCND. Krikke et al. [2003] propose a Mixed-Integer Linear Program (MILP) whose decision variables concern both network design and product design. They analyze interactions between both types of variables and conclude that logistics network structure has most impact on costs, whereas product design has most impact on energy and waste. Abdallah et al. [2013] observe that price of raw material increases as the product becomes greener. Thus, supplier selection has contradictory impact on cost and environmental dimension [Kumar et al., 2014]. Amin and Zhang [2013] assess impact of choosing environmentally-friendly materials in the production process.

\subsubsection{Performance measures}

According to Krikke et al. [2003] or Harraz and Galal [2011], given LCA complexity, it becomes regular practice to use more pragmatic indicators such as residual waste and energy used.

Ahi and Searcy [2015] identified 2555 unique metrics to measure performance in green and sustainable supply chains. Due to lack of a generic assessment methodology, a wide range of ad hoc performance measures have been developed to assess environmental performance of a supply chain, so that identifying the most appropriate performance measures is still a challenging issue [Nikolopoulou and Ierapetritou, 2012 .

Table 6 details the metrics found in the reference papers for assessing the environmental impact. Columns 2-6 report various families of performance measures: GHG emissions (column 2), amount of waste generated (column 3), energy consumption (column 4), amount of material recycled (column 5) and others measures (column 6).

\section{- Carbon footprint}

The most popular metric for measuring environmental impact is the carbon footprint, which is the total amount of GHG emitted by a company or a supply chain (25 papers). All GHG emissions may be considered, but for practical reasons, baseline indicators with only $\mathrm{CO}_{2}, \mathrm{CH}_{4}$ and $\mathrm{N}_{2} \mathrm{O}$ are also used [Wright et al., 2011]. For example, Jamshidi et al. [2012] consider two objective functions: 
Table 6: Metrics used for partial assessment of environmental impact

\begin{tabular}{|c|c|c|c|c|c|}
\hline Article & $\begin{array}{c}\text { GHG } \\
\text { emissions }\end{array}$ & Waste & $\begin{array}{l}\text { Energy } \\
\text { use }\end{array}$ & $\begin{array}{l}\text { Material } \\
\text { recovery }\end{array}$ & Others \\
\hline $\begin{array}{l}\text { Ramudhin et al. [2010] } \\
\text { Chaabane et al. [2011] } \\
\text { Krikke [2011] } \\
\text { Wang et al. [2011] } \\
\text { Elhedhli and Merrick [2012] } \\
\text { Jamshidi et al. [2012] } \\
\text { Kannan et al. [2012] } \\
\text { Mallidis et al. [2012] } \\
\text { Abdallah et al. [2013] } \\
\text { Diabat et al. [2013] } \\
\text { Govindan et al. [2013] } \\
\text { Kanzian et al. [2013] } \\
\text { Sadrnia et al. [2013] } \\
\text { Xifeng et al. [2013] } \\
\text { Zhang et al. [2013] } \\
\text { Baud-Lavigne et al. [2014] } \\
\text { Marufuzzaman et al. [2014] } \\
\text { Saffar et al. [2014] } \\
\text { Saffar et al. [2015] } \\
\text { Caruso et al. [1993] } \\
\text { Berger et al. [1999] } \\
\text { Lira-Barragán et al. [2011] } \\
\text { Pishvaee et al. [2012a] } \\
\text { Eskandarpour et al. [2013] } \\
\text { Galante et al. [2010] } \\
\text { Pati et al. [2008] } \\
\text { Lira-Barragán et al. [2013] } \\
\text { Verma et al. [2013] }\end{array}$ & $\begin{array}{l}0 \\
0 \\
0 \\
0 \\
0 \\
0 \\
0 \\
0 \\
0 \\
0 \\
0 \\
0 \\
0 \\
0 \\
0 \\
0 \\
0 \\
0 \\
0\end{array}$ & $\begin{array}{l}\bullet \\
\bullet \\
\bullet\end{array}$ & • & - & $\stackrel{0}{\bullet}$ \\
\hline $\begin{array}{l}\text { Alçada-Almeida et al. [2009] } \\
\text { Liu et al. [2011] } \\
\text { Lam et al. [2013] } \\
\text { Devika et al. [2014] } \\
\text { Harris et al. [2011] } \\
\text { Tuzkaya et al. [2011] } \\
\text { Krikke et al. [2003] } \\
\text { Harraz and Galal [2011] } \\
\text { Amin and Zhang [2013] } \\
\text { Corsano et al. [2011] } \\
\text { Papapostolou et al. [2011] }\end{array}$ & $\begin{array}{l}0 \\
0 \\
0 \\
0 \\
0 \\
0\end{array}$ & ?ִ & $\begin{array}{l}0 \\
0 \\
0 \\
0 \\
0\end{array}$ & $\begin{array}{l}\bullet \\
\bullet\end{array}$ & ○ \\
\hline $\begin{array}{l}\text { Costi et al. [2004] } \\
\text { Erkut et al. [2008] } \\
\text { Minciardi et al. [2008] } \\
\text { Bouzembrak et al. [2013] } \\
\text { Mohammadi et al. [2014] }\end{array}$ & $\begin{array}{l}\bullet \\
\bullet \\
\bullet \\
\bullet\end{array}$ & ? & $\bullet$ & $\begin{array}{l}\bullet \\
\bullet \\
\bullet\end{array}$ & 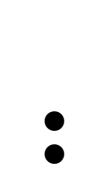 \\
\hline Pourmohammadi et al. [2008] & & $\bullet$ & - & $\bullet$ & $\bullet$ \\
\hline
\end{tabular}


one minimizes the total costs within the supply chain and the other one minimizes dangerous gases produced, such as $\mathrm{NO}_{2}, \mathrm{CO}$ and Volatile Organic Compounds.

GHG emissions are not always calculated explicitly. In Pourmohammadi et al. [2008] the amount of GHG emitted is considered through an input-output approach to estimate the cost of air pollution. In Harris et al. [2011], the quantity of energy used is a mean to estimate GHG emissions.

- Waste generated, energy use, material recovery and other measures

Environmental performance can be measured by many possible criteria which generally arise from the economic sector concerned. The quantity of waste generated is mentioned in 16 papers, the use of energy is included in 8 models and the material recovery in 7 models. For example, Pati et al. [2008] measure the value of wastepaper recovered by a paper recycling system. Amin and Zhang [2013] measure the use of renewable and recycled energy, such as solar power. Finally, 7 papers use criteria that cannot be classified in the preceding categories. Other metrics include use of water [Caruso et al., 1993, Lira-Barragán et al., 2013, Papapostolou et al., 2011], noise pollution [Bouzembrak et al., 2013, Mohammadi et al., 2014] or an overall estimation of long-term impact and cleanup cost of oil-spill caused by vessels [Verma et al., 2013]. Pourmohammadi et al. [2008] measure a virgin material opportunity costs which is the extra expense that a firm is willing to pay when it refuses to substitute the virgin material market by an acceptable recycled material. Other metrics are sometimes not detailed, such as the land specific technical requirement in Tuzkaya et al. [2011].

\subsection{Conclusion}

The integration of environmental criteria in SCND is a natural idea for activities with a high impact. The 83 papers dealing with environmental SCND share almost equally between LCA (39) and non-LCA (44) approaches. The most popular LCIA methods are Eco-Indicator 99 and Impact 2002+. To our knowledge, ReCipe has been used only in Mota et al. [2014]. Since it is a more recent method and it provides a single score, more authors are likely to use it in forthcoming years. As far as impact indicators are concerned, GWP is particularly designed for very long-horizon activities such as process industries or fuel/energy supply chains. Other indicators are used when they are relevant for their respective domain of application. Non-LCA approaches measure environmental performance on tangible domains (facilities, transport, product design) and measures (GHG emission, waste produced, energy used etc.). This goes along with a collection of various ad hoc measures depending on the application considered.

Finally, let us point out 2 papers about sustainable extensions to special facility location problems: the hub location problem [Mohammadi et al., 2014] and the location routing problem [Govindan et al., 2013]. Incorporating environmental criteria into these problems seems to be a novel research issue.

\section{Social Supply Chain Network Design}

Social sustainability has been examined to a far lesser degree than environmental or green supply chain management [Seuring and Müller, 2008]. Furthermore the definition of social sustainability itself is still under development [Benoit-Norris, 2014]. Social sustainability in supply chains addresses issues of social justice and human rights with studies focusing on practices such as supplier human rights actions, labor conditions, codes of practices and social auditing, supplier compliance with child labor laws, and the delivery of social equity through sourcing from diverse suppliers in terms of gender, size, ethnicity and avoidance of conflicts of interest. Including social aspects in network design decisions allows to better evaluate the impact of a supply chain on its stakeholders: employees, customers and local communities. This also helps obtaining consistency between qualitative and quantitative decisions. 
We analyze 13 references papers having an assessment of social impact with the framework proposed in Chardine-Baumann and Botta-Genoulaz [2014]. The Table 7 presents this classification. Columns 2 to 4 correspond to 3 of the 5 fields proposed in Chardine-Baumann and Botta-Genoulaz [2014]. It is worth noting than no paper addresses the two last fields: human rights (child and forced labor, freedom of association, discrimination) and business practice (fight against corruption, fair-trading, promotion of corporate social responsibility in the sphere of influence). Reference papers followed by a ${ }^{*}$ do not include the environmental dimension.

Table 7: Models with the social dimension

\begin{tabular}{lccc}
\hline Article & $\begin{array}{c}\text { Work } \\
\text { conditions }\end{array}$ & $\begin{array}{c}\text { Societal } \\
\text { commitment }\end{array}$ & $\begin{array}{c}\text { Customer } \\
\text { issues }\end{array}$ \\
\hline Harraz and Galal [2011] & $\bullet$ & & \\
Pérez-Fortes et al. [2012] & $\bullet$ & & \\
Pishvaee et al. [2012a] & $\bullet$ & & \\
You et al. [2012] & $\bullet$ & & \\
Devika et al. [2014] & $\bullet$ & & \\
Mota et al. [2014] & $\bullet$ & & \\
Santibañez-Aguilar et al. [2014] & $\bullet$ & $\bullet$ \\
Yue et al. [2014] & & $\bullet$ \\
Caruso et al. [1993] & & $\bullet$ \\
Datta [2012]* & & $\bullet$ & $\bullet$ \\
Bouzembrak et al. [2013] & & $\bullet$ \\
Beheshtifar and Alimoahmmadi [2014]* & & $\bullet$ \\
Tuzkaya et al. [2011] & $\bullet$ & $\bullet$ \\
Dehghanian and Mansour [2009] & $\bullet$ & & \\
\hline
\end{tabular}

In the field work conditions, employment is the main social indicator used in literature. The number of jobs created is considered by most authors, with slight variations. Mota et al. [2014] define a social benefit indicator which prefers job creation in the less developed regions. Devika et al. [2014] distinguish the fixed jobs opportunities (which are independent of the level of activity) from the variables jobs (which increase with the level of activity). Dehghanian and Mansour [2009] aim at creating jobs in the widest range of communities. They maximize the number of facilities installed, which corresponds to the idea of fixed jobs in Devika et al. [2014]. The damage to workers and security measures, such as the exposure to chemical elements is considered in Dehghanian and Mansour [2009] and Pishvaee et al. [2012a].

The Societal commitment field regroups all decisions contributing to improve a population's health, education, culture [Datta, 2012]. It includes local development policies [Dehghanian and Mansour, 2009], equity in access to healthcare [Beheshtifar and Alimoahmmadi, 2014], the impact of the supply chain on real estate [Bouzembrak et al., 2013], but also the political opposition [Caruso et al., 1993, Tuzkaya et al., 2011].

The field customer issues regroup all impacts individually affecting each customers. Malczewski and Ogrycżak [1990] consider the environmental pollution at hospital sites as a social criterion since its impact relates directly to patients and users. In Dehghanian and Mansour [2009], the customer issue concerns the risk of using recycled material.

As pointed by several previous reviews, including social concerns into sustainable SCND models raises many modeling and assessment difficulties. First of all, social responsibility is a fully multi-disciplinary and multi-stakeholder issue [Pishvaee et al., 2012a]. As a consequence, social performance is generally hard to model with pertinent quantitative indicators. For example, Chaabane et al. [2012] state that tangible indicators such as noise and pollution can play the role of indicators of both environmental and social performance. However, they do not integrate them in their MILP since they do not identify good measures of social sustainability. Moreover, social and environmental impacts sometimes strongly 
interact. Pishvaee et al. [2012a] aggregate three social impacts and one environmental impact (amount of waste generated) into a single indicator. Since the social impact is often qualitative by nature, it is difficult to build a single metric to measure it. Multi-Criteria Decision Making (MCDM) can be a suitable tool to overcome this problem. Dehghanian and Mansour [2009] aggregate their four social criteria into a single indicator with an Analytical Hierarchy Process (AHP) [Saaty, 1990]. AHP is also used in Datta [2012]. Hence, selecting the most appropriate criteria and incorporating them into mathematical models are still challenging issues.

\section{Modeling Approaches}

In this section, we review the main characteristics of mathematical models for sustainable supply chain design problems. Such problems have resulted in a large variety of models. This can be explained not only by the variety of industrial contexts (single or multiple period, single or multiple products, structure of the logistics network), but also by modeling issues: single or multiple objectives, deterministic or uncertain data.

The main decision variables in SCND models are binary variables concerning the location of facilities, sizing decisions, the selection of suitable technology levels and the selection of transportation modes between facilities. Since product flows along the supply chain are generally modeled by continuous constraint, the SCND models are often mixed-integer formulations, which can be linear or nonlinear. Some stochastic models are also found that enable the consideration of uncertainties such as the demand level.

The section is organized into two parts. In section 5.1, we review the models with a single objective function. This objective can be either economic or environmental, but is never social only. Multi-objective models are then described in section 5.2. Both sections are divided into two subsections, describing deterministic and stochastic models, respectively.

\subsection{Models with a single objective}

The easiest way to incorporate environmental issues into classic SCND models is to express the objective function as a weighted average of all objective functions. This requires applying conversion factors to convert non-homogeneous measures into a single one.

For example, when the whole environmental impact can be expressed through a quantity of GHG emissions, it is possible to convert the environmental impact into its monetary equivalent by using conversion factors. Then the monetized environmental damage can be aggregated with the economic objective into a single objective.

The main characteristics of single objective deterministic and stochastic models are summarized in Table 8 .

\subsubsection{Deterministic models}

As mentioned above, some authors consider the economic objective as the main one and represent the environmental dimension by constraints in their models. These constraints may express a maximal authorized level of GHG emissions. For example, the objective function in Elia et al. [2011] is to minimize the cost of facility investment, feedstock purchase and transportation. The authors introduce an environmental constraint by imposing an overall GHG emission target level for each hybrid coal, biomass and natural liquid gas plant. Papapostolou et al. [2011] consider a pure economic objective function. Environmental constraints limiting the land use and water consumption are included in their linear model.

Other authors mix economic and environmental criteria into the objective function. In Elhedhli and Merrick [2012], the objective function includes two terms related to pollution cost and three terms 
Table 8: Models with single objective

\begin{tabular}{|c|c|c|c|c|}
\hline Article & Dimensions & $\begin{array}{l}\text { Multi- } \\
\text { product }\end{array}$ & $\begin{array}{l}\text { Multi- } \\
\text { period }\end{array}$ & $\begin{array}{l}\text { Multi- } \\
\text { mode }\end{array}$ \\
\hline \multicolumn{5}{|l|}{ Linear models } \\
\hline Krikke [2011] & Eco - Env & & & \\
\hline Datta [2012] & Eco - Soc & & & \\
\hline Elhedhli and Merrick [2012] & Eco - Env & & & \\
\hline Kannan et al. [2012] & Eco - Env & & & \\
\hline Bloemhof-Ruwaard et al. [1996] & Eco - Env & ○ & & \\
\hline Liu et al. [2011] & Eco - Env & ○ & & \\
\hline Papapostolou et al. [2011] & Eco - Env & 0 & & \\
\hline Abdallah et al. [2012] & Eco - Env & 0 & & \\
\hline Abdallah et al. [2013] & Eco - Env & ○ & & \\
\hline Amin and Zhang [2013] & Eco - Env & 0 & & \\
\hline Diabat et al. [2013] & Eco - Env & ○ & & \\
\hline Mallidis et al. [2012] & Eco - Env & & & 0 \\
\hline Bouzembrak et al. [2013] & Eco - Env - Soc & & & ○ \\
\hline Elia et al. [2011] & Eco - Env & ○ & & ○ \\
\hline Elia et al. [2012] & Eco - Env & ○ & & ○ \\
\hline Elia et al. [2014] & Eco - Env & $\bullet$ & & ○ \\
\hline \multicolumn{5}{|l|}{ Stochastic linear models } \\
\hline Verma et al. [2013] & Eco - Env & & & \\
\hline Giarola et al. [2012a] & Eco - Env & 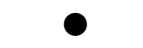 & 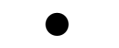 & \\
\hline \multicolumn{5}{|l|}{ Non-linear models } \\
\hline Lira-Barragán et al. [2013] & Eco - Env & & & \\
\hline Verma et al. [2013] & Eco - Env & & & \\
\hline Costi et al. [2004] & Eco - Env & 0 & & \\
\hline Corsano et al. [2011] & Eco - Env & 0 & & \\
\hline Lira-Barragán et al. [2011] & Eco - Env & $\bullet$ & & \\
\hline
\end{tabular}


related to the cost of logistics operations. In Abdallah et al. [2012] and Kannan et al. [2012] the objective function is the sum of various logistics costs and an additional term associated with $\mathrm{CO}_{2}$ emissions above the amount allocated by the government.

Lira-Barragán et al. [2011] minimize the total annual cost of a new industrial plant which impacts the water quality throughout a surrounding watershed. The objective function includes the wastewater treatment costs whereas the water quality appears as a constraint. Mallidis et al. [2012] propose a model with several objective functions related to cost, and the emission of $\mathrm{CO}_{2}$ or particulate matters (fine dust). The model is solved with each objective being considered one by one.

Note that Krikke [2011] proposes a linear variant of mixed integer programming: binary facility location variables are pre-fixed, resulting in one linear program for each scenario.

In some of the reference papers, the technical context leads to the formulation of nonlinear models. Costi et al. [2004] propose an MINLP model for the location of treatment facilities for solid waste management. The objective function concerns the economic cost and environmental issues are modeled as constraints. The binary decision variables concern the existence of facilities. Continuous variables model the material flows between facilities. Non-linearity comes from multiplications between continuous variables. Corsano et al. [2011] consider ethanol plant design and ethanol supply chain design simultaneously. Non-linearity arises from some non-convex constraints in the ethanol plant design model.

\subsubsection{Stochastic models}

By definition, sustainable SCND models aim at impacting the structure of the logistics network of a company in the long term. It is therefore realistic to expect to face uncertainties in the analysis of the problem. This is particularly true for the consideration of the uncertainties on the level of customer demands within a strategic planning horizon. Other factors such as transportation costs or the amount of waste or emissions generated or returned products may also be considered as uncertain parameters. Moreover, the data available at the moment strategic decisions are made are generally aggregated and lose accuracy as the time horizon recedes. A survey on the inclusion of stochastic components in facility location models is proposed by Snyder [2004].

However we found only two references of single objective stochastic models for sustainable SCND problems. Giarola et al. [2012a] propose a MILP for the design of a bio-ethanol supply chain, in which the costs of carbon and biomass are considered as uncertain parameters. To overcome this uncertainty, a two-stage stochastic programming approach is used. Verma et al. [2013] present a two-stage stochastic programming approach which tackles both the location and stockpile of equipment at emergency response facilities that deal with potential oil-spill emergencies on the south cost of Newfoundland in Canada. Their model includes two variants corresponding to linear and non-linear formulation of equipment acquisition cost.

\subsection{Multi-objective models}

\subsubsection{Deterministic models}

The deterministic multi-objective models for sustainable SCND are summarized in Table 9 (linear models) and Table 10 (non-linear models)

In practice, most sustainable SCND models are bi-objective linear models. Many authors see the economic objective as the traditional objective function, whereas the environmental or social objectives are considered as extensions of the traditional single objective models. A frequent modeling approach is to consider one economic objective and one environmental objective such as minimizing GHG emissions.

Amin and Zhang [2013] extend their mono-objective model by considering an additional environmental objective. In the area of domestic waste treatment, Berger et al. [1999] propose a comprehensive multi-periodic MILP model for the strategic design and tactical planning of an integrated regional solid 
Table 9: Deterministic multi-objective linear models

\begin{tabular}{|c|c|c|c|c|}
\hline Article & Dimensions & $\begin{array}{c}\text { multi- } \\
\text { product }\end{array}$ & $\begin{array}{l}\text { multi- } \\
\text { period }\end{array}$ & $\begin{array}{l}\text { multi- } \\
\text { mode }\end{array}$ \\
\hline Malczewski and Ogrycżak [1990] & Eco-Soc & & & \\
\hline Caruso et al. [1993] & Eco-Env-Soc & & & \\
\hline Erkut et al. [2008] & Eco-Env & & & \\
\hline Minciardi et al. [2008] & Eco-Env & & & \\
\hline Alçada-Almeida et al. [2009] & Eco-Env & & & \\
\hline Dehghanian and Mansour [2009] & Eco-Env-Soc & & & \\
\hline Galante et al. [2010] & Eco-Env & & & \\
\hline Tuzkaya et al. [2011] & Eco-Env-Soc & & & \\
\hline Pozo et al. [2012] & Eco-Env & & & \\
\hline Xifeng et al. [2013] & Eco-Env & & & \\
\hline Govindan et al. [2013] & Eco-Env & & & \\
\hline Devika et al. [2014] & Eco-Env-Soc & & & \\
\hline Krikke et al. [2003] & Eco-Env & ○ & & \\
\hline Pati et al. [2008] & Eco-Env & 0 & & \\
\hline Quariguasi Frota Neto et al. [2008] & Eco-Env & 0 & & \\
\hline Harraz and Galal [2011] & Eco-Env-Soc & $\mathbf{0}$ & & \\
\hline Amin and Zhang [2013] & Eco-Env & 0 & & \\
\hline Lam et al. [2013] & Eco-Env & 0 & & \\
\hline Baud-Lavigne et al. [2014] & Eco-Env & 0 & & \\
\hline Hugo et al. [2005] & Eco-Env & & - & \\
\hline Jamshidi et al. [2012] & Eco-Env & & & $\bullet$ \\
\hline Kanzian et al. [2013] & Eco-Env & & & 0 \\
\hline Sadrnia et al. [2013] & Eco-Env & & & 0 \\
\hline Hugo and Pistikopoulos [2005] & Eco-Env & ○ & $\bullet$ & \\
\hline Pourmohammadi et al. [2008] & Eco-Env & 0 & 0 & \\
\hline Mele et al. [2009] & Eco-Env & 0 & 0 & \\
\hline Bojarski et al. [2009] & Eco-Env & 0 & 0 & \\
\hline Pinto-Varela et al. [2011] & Eco-Env & $\mathbf{0}$ & 0 & \\
\hline Zamboni et al. [2011] & Eco-Env & 0 & 0 & \\
\hline Giarola et al. [2012b] & Eco-Env & 0 & 0 & \\
\hline Pérez-Fortes et al. [2012] & Eco-Env-Soc & 0 & 0 & \\
\hline Zamboni et al. [2009] & Eco-Env & 0 & & $\bullet$ \\
\hline Ramudhin et al. [2010] & Eco-Env & $\mathbf{0}$ & & $\mathbf{0}$ \\
\hline Chaabane et al. [2011] & Eco-Env & 0 & & 0 \\
\hline Mota et al. [2014] & Eco-Env-Soc & 0 & & 0 \\
\hline Marufuzzaman et al. [2014] & Eco-Env & & ○ & 0 \\
\hline Berger et al. [1999] & Eco-Env & $\mathbf{0}$ & 0 & 0 \\
\hline Duque et al. [2010] & Eco-Env & 0 & 0 & 0 \\
\hline Guillén-Gosálbez et al. [2010] & Eco-Env & 0 & 0 & 0 \\
\hline Giarola et al. [2011] & Eco-Env & 0 & 0 & 0 \\
\hline Mele et al. [2011] & Eco-Env & 0 & 0 & 0 \\
\hline You and Wang [2011] & Eco-Env & 0 & 0 & 0 \\
\hline Akgul et al. [2012] & Eco-Env & 0 & 0 & 0 \\
\hline Chaabane et al. [2012] & Eco-Env & 0 & 0 & 0 \\
\hline Kostin et al. [2012] & Eco-Env & 0 & 0 & 0 \\
\hline You et al. [2012] & Eco-Env-Soc & 0 & 0 & 0 \\
\hline Bernardi et al. [2013] & Eco-Env & 0 & 0 & $\bullet$ \\
\hline Santibañez-Aguilar et al. [2014] & Eco-Env-Soc & 0 & $\bullet$ & 0 \\
\hline
\end{tabular}


waste management planning. The model considers several types of treatment technologies and sites for treatment and land-fill as well as the possibility of recycling waste on the markets. Several environmental parameters and indicators may be used.

Chaabane et al. [2012] propose a bi-objective model for the design of an aluminum supply chain. A carbon credit component is included in the economic objective, whereas the second objective is to minimize the GHG emissions. The model also considers tactical issues such as inventory control decisions. Akgul et al. [2012] propose a multi-period, multi-product MILP model for the optimization of a biofuel supply chain regarding cost and environmental issues. All stages of the biofuel life-cycle, such as cultivation, transportation and production, are integrated into the proposed model. Quariguasi Frota Neto et al. [2008] propose a bi-objective model to assess the flow of materials, the amount of production at each plant and to select the most suitable end-of-use alternatives, such as refurbishing and recycling. Guillén-Gosálbez et al. [2010] develop a bi-objective MILP model for a hydrogen supply chain design. The influence of the hydrogen network operation on climate change is investigated as an environmental issue. In chance-constrained programming, the models embed the probability of satisfying constraints subject to uncertain data. The model considers capacity expansion (see also Hugo et al. [2005]).

A two-echelon multiple-vehicle location-routing problem with time windows for optimization of sustainable supply chain network of perishable food is studied by Govindan et al. [2013]. They propose a deterministic model involving an economic goal for the minimization of all fixed and variable costs and an environmental goal for the global minimization of environmental impacts of opening manufacturing and distribution facilities and for the emissions due to shipments between facilities.

Very few models have more than three objective functions. Erkut et al. [2008] develop a multicriteria facility location model for the municipal solid wastes management at the regional level in North Greece. Their MILP model includes 5 objective functions : 1 relative to minimum total cost of facilities implementation and flows, and 4 related to the environmental impacts (GHC effects, landfilling, energy and materials recovery. A solution to the model consists of locations and technologies for transfer stations, material recovery facilities, incinerators and sanitary landfills, as well as the waste flow between these locations.

Table 10: Deterministic multi-objective non-linear models

\begin{tabular}{|c|c|c|c|c|}
\hline Article & Dimensions & $\begin{array}{c}\text { multi- } \\
\text { product }\end{array}$ & $\begin{array}{l}\text { multi- } \\
\text { period }\end{array}$ & $\begin{array}{l}\text { multi- } \\
\text { mode }\end{array}$ \\
\hline $\begin{array}{l}\text { Beheshtifar and Alimoahmmadi [2014] } \\
\text { Guillén-Gosálbez et al. [2008] } \\
\text { Muñoz et al. [2013] } \\
\text { Zhang et al. [2013] }\end{array}$ & $\begin{array}{l}\text { Eco-Soc } \\
\text { Eco-Env } \\
\text { Eco-Env } \\
\text { Eco-Env }\end{array}$ & 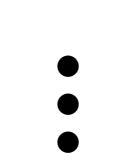 & • & • \\
\hline $\begin{array}{l}\text { Eskandarpour et al. [2013] } \\
\text { Wang et al. [2011] } \\
\text { Yue et al. [2014] } \\
\text { Liu et al. [2011] } \\
\text { Yue et al. [2013] }\end{array}$ & $\begin{array}{l}\text { Eco-Env } \\
\text { Eco-Env } \\
\text { Eco-Env-Soc } \\
\text { Eco-Env } \\
\text { Eco-Env }\end{array}$ & 0 & 0 & ○ \\
\hline
\end{tabular}

Only a few bi-objective models are non-linear. In Beheshtifar and Alimoahmmadi [2014], one of the objective is to minimize the standard deviation of distances from the place of demand points to the open facilities. Due to economies of scale, Zhang et al. [2013] includes non-linear $\mathrm{CO}_{2}$ emissions due to transportation. In the last five references in the Table, the models can be linearized. Yue et al. [2014] and Yue et al. [2013] linearize their model with the Charnes-Cooper transformation and Glover's linearization. The authors compare the performance of the linear and non-linear formulations of their models. 


\subsubsection{Stochastic models}

Like many supply chain management problems, SCND problems are subject to uncertainty. Uncertainty can have many different sources, like the level of demand or the proportion of returned products in closedloop supply chains. Uncertainty can also affect the outputs and depend on the performance of the process. Such an example is the level of GHG emissions. As pointed out by Guillén-Gosálbez and Grossmann [2009], many uncertainties exist in the life-cycle inventory but many LCA methods assume nominal values for the input data. These authors mention however that the Eco-indicator 99 methodology is affected by three main sources of uncertainty: the operational or data uncertainty, but also the fundamental or model uncertainties, and the uncertainty on the completeness on the model. If well taken into account, uncertainty will impact the design of a supply chain. The number and size of production and transport facilities clearly depends on the mean values of input data, but also of their possible variation. Uncertainty will also affect the evaluation of a supply chain in terms of costs, GHG emissions, etc.

The stochastic multi-objective models encountered in our review are summarized in Table 11.

Table 11: Stochastic multi-objective models

\begin{tabular}{lcccc}
\hline Article & Dimensions & $\begin{array}{c}\text { Multi- } \\
\text { product }\end{array}$ & $\begin{array}{c}\text { Multi- } \\
\text { period }\end{array}$ & $\begin{array}{c}\text { Multi- } \\
\text { mode }\end{array}$ \\
\hline Linear models & & & & \\
\hline Pishvaee et al. [2012a] & Eco - Env - Soc & & & \\
Ruiz-Femenia et al. [2013] & Eco - Env & $\bullet$ & $\bullet$ & \\
Saffar et al. [2014] & Eco - Env & $\bullet$ & $\bullet$ & \\
Saffar et al. [2015] & Eco - Env & $\bullet$ & $\bullet$ & \\
Pishnaee and Razmi [2012] & Eco - Env & & & $\bullet$ \\
Pishraee et al. [2012b] & Eco - Env & & & \\
Amin and Zhang [2013] & Eco - Env & $\bullet$ & & \\
\hline Non-linear models & & & $\bullet$ \\
\hline Guillén-Gosálbez and Grossmann [2009] & Eco - Env & $\bullet$ & $\bullet$ \\
Guillén-Gosálbez and Grossmann [2010] & Eco - Env & $\bullet$ & $\bullet$ \\
Mohammadi et al. [2014] & Eco - Env & & & \\
\hline
\end{tabular}

In Pishvaee et al. [2012a], a first objective function minimizes a sum of logistics costs and a second objective function aggregates the four social and environmental impacts already presented in section 4 . Amin and Zhang [2013] extend their deterministic model by considering uncertain demand and amount of returned products. They use a scenario-based stochastic programming approach.

Ruiz-Femenia et al. [2013] study the effect of demand uncertainty on the economic and environmental performance of supply chains. Their model seeks to maximize the expected profit and minimize the probability for environmental factors to exceeding a given limit.

Guillén-Gosálbez and Grossmann [2009] provide a MINLP model to maximize the net present value and minimize the environmental impact for chemical supply chains, with uncertainty about the amount of emissions released and the feedstock requirement. In Guillén-Gosálbez and Grossmann [2010], the value of damage factors is considered an uncertain parameter so a chance-constraint model is applied to handle them.

Mohammadi et al. [2014] propose a novel variant of the hub location model called the sustainable hub location problem (SHLP) in which two new environmental-based cost functions accounting for air and noise pollution of vehicles are incorporated and related to fuel consumption. The cost of emission at the hubs is also considered. To cope with uncertain data incorporated in the model, a mixed possi- 
bilistic-stochastic programming approach is proposed to construct the crisp counterpart, resulting in a mixed integer nonlinear programming (MINLP) optimization model according to the nonlinear form of the objective functions.

Fuzzy set theory [Zadeh, 1978] provides an efficient tool to capture the imprecision of data. It is employed when there are not enough historical data to estimate probability distribution functions of uncertain parameters. This approach is chosen in Pishvaee and Razmi [2012], Pishvaee et al. [2012a] and Pishvaee et al. [2012b].

Pinto-Varela et al. [2011] model two case studies in a Portuguese industry with multiple products and periods. Their approach includes a fuzzy-like modeling to indicate the trade-off between the economic and environmental objectives considered. Like in Guillén-Gosálbez and Grossmann [2009], the stochastic model is converted into a deterministic one to facilitate its solution.

\subsection{Conclusions on modeling}

In summary, a large variety of modeling techniques have been used in order to address sustainable SCND problems among which most used techniques are MIP for linear or non linear problems. Non linearity often arises from the modeling of non-linear industrial processes.

Some models consider a single objective aggregating the economic and environmental or sometimes social factors. However most of the models explicitly consider two or three different objectives functions (or sometimes more), which is natural to cope with the different dimensions of sustainable development. Since the social impact can be difficult to quantify, it is sometimes not addressed explicitly into a mathematical model, but rather in a preliminary step of scenario definition or in a post-optimization evaluation of the solutions.

\section{Solution Methods}

The goal of this section is to review the solution methods and the tools employed for solving sustainable SCND models. SCND problems are NP-hard [Pishvaee et al., 2010], since they generalize facility location problems. However, instances of average size are still tractable by mathematical solvers. Thus a large variety of solution methods are used. This section is divided into three subsections. Subsection 6.1 reviews the methods used for solving single-objective models. This includes multi-objective models for which the objective function is a weighted sum of the objectives. Subsection 6.2 is devoted to methods for multi-objective models: $\varepsilon$-constraint, metaheuristics, multi-criteria decision analysis (MCDA), and other methods. Finally, subsection 6.3 describes the use of modeling tools and solvers in all reference papers.

\subsection{Solution methods for models with a single objective}

Heuristics and metaheuristics are widely applied in the SCND literature, but still rarely employed in sustainable SCND. Elhedhli and Merrick [2012] use Lagrangean relaxation to decompose their threeechelon model into a capacitated facility location problem with single sourcing and a concave knapsack problem that can be solved easily. The Lagrangean relaxation is completed with a Lagrangean heuristic which finds a near-optimal solution for a set of instances with up to 10 suppliers, 20 plants and 150 customers. Tuzkaya et al. [2011] use the weighted sum to integrate the two objective functions of their bi-objective model. Then they resort to a genetic algorithm to solve single objective models.

\subsection{Solution methods for multi-objective models}

The multi-objective methods for solving sustainable SCND models are summarized in Table 12. 
Table 12: Solution methods for multi-objective models

\begin{tabular}{|c|c|}
\hline Type of method & Articles \\
\hline $\begin{array}{l}\text { Weighted sum of objec- } \\
\text { tives }\end{array}$ & $\begin{array}{l}\text { Caruso et al. [1993], Krikke et al. [2003], Bojarski et al. [2009], } \\
\text { Galante et al. [2010], Amin and Zhang [2013], Bernardi et al. } \\
\text { [2013], Kanzian et al. [2013], Marufuzzaman et al. [2014] }\end{array}$ \\
\hline$\varepsilon$-constraint & $\begin{array}{l}\text { Guillén-Gosálbez et al. [2008], Guillén-Gosálbez and Grossmann } \\
\text { [2009], Mele et al. [2009], Duque et al. [2010], Guillén-Gosálbez } \\
\text { and Grossmann [2010], Guillén-Gosálbez et al. [2010], Chaabane } \\
\text { et al. [2011], Mele et al. [2011], You and Wang [2011], Akgul et al. } \\
\text { [2012], Kostin et al. [2012], Pérez-Fortes et al. [2012], You et al. } \\
\text { [2012], Pishvaee and Razmi [2012], Pishvaee et al. [2012a], Pozo } \\
\text { et al. [2012], Amin and Zhang [2013], Ruiz-Femenia et al. [2013], } \\
\text { Xifeng et al. [2013], Yue et al. [2013], Baud-Lavigne et al. [2014], } \\
\text { Marufuzzaman et al. [2014], Mota et al. [2014], Santibañez-Aguilar } \\
\text { et al. [2014], Yue et al. [2014] }\end{array}$ \\
\hline Goal Programming & $\begin{array}{l}\text { Alçada-Almeida et al. [2009], Galante et al. [2010], Pati et al. } \\
\text { [2008], Ramudhin et al. [2010], Chaabane et al. [2011], Harraz } \\
\text { and Galal [2011] }\end{array}$ \\
\hline Interactive fuzzy approach & $\begin{array}{l}\text { Malczewski and Ogrycżak [1990], Pinto-Varela et al. [2011], Pish- } \\
\text { vaee et al. [2012b] }\end{array}$ \\
\hline Metaheuristics & $\begin{array}{l}\text { GA: Dehghanian and Mansour [2009], Tuzkaya et al. [2011], } \\
\text { Zhang et al. [2013], MA: Jamshidi et al. [2012], VNS: Eskan- } \\
\text { darpour et al. [2013], Devika et al. [2014], PSO: Govindan et al. } \\
\text { [2013], SA+ICA: Mohammadi et al. [2014] } \\
\text { NSGA II+TOPSIS: Beheshtifar and Alimoahmmadi [2014] } \\
\text { NSGA II+Fuzzy: Saffar et al. [2014] NSGA II+E-constraint: } \\
\text { Saffar et al. [2015] }\end{array}$ \\
\hline Others & $\begin{array}{l}\text { Hugo and Pistikopoulos [2005], Erkut et al. [2008], Minciardi et al. } \\
\text { [2008], Quariguasi Frota Neto et al. [2008], Zamboni et al. [2009], } \\
\text { Galante et al. [2010], Wang et al. [2011], Datta [2012], Sadrnia } \\
\text { et al. [2013] }\end{array}$ \\
\hline
\end{tabular}




\section{Weighted sum of objectives}

An intuitive approach to handle multi-objective models is to weight each criterion and to minimize the weighted sum of all criteria. The main advantage of this approach is to model and solve multi-objective problems with single-objective approaches. Unfortunately, this modeling may not represent the decisionmaker's interest and may modify the Pareto structure of the problem [Pozo et al., 2012]. It can be used only when the Pareto set is convex. Such an approach is chosen in Bernardi et al. [2013] where the three conflicting objectives are the economic one, the impact on global warming, and the impact on water resources.

Pinto-Varela et al. [2011] use a symmetric fuzzy linear programming (SFLP) for a bi-objective model. The model maximizes a single variable $0 \leq \lambda \leq 1$ representing the degree to which each objective must be satisfied.

\section{Epsilon-constraint}

The $\varepsilon$-constraint method consists in prioritizing a primary objective while expressing other objectives as constraints. Fixing various values of constraint enables the Pareto front to be approximated. This method is well adapted to the extension of a single-objective economic approach to bi-objective models integrating environmental or social criteria. Indeed, by considering the economic model as the primary objective, this approach enables decision makers to measure the financial impact of environmental or social constraints.

The model in Pérez-Fortes et al. [2012] includes economic, social and environmental criteria. Since the social metric is discrete, only the environmental criterion is represented in the $\varepsilon$-constraint and the authors represent one Pareto front for each possible value of the social metric.

Guillén-Gosálbez and Grossmann [2009] and Guillén-Gosálbez and Grossmann [2010] propose bicriteria MINLPs. In Guillén-Gosálbez and Grossmann [2009], the environmental criterion is transferred to the $\varepsilon$-constraint. The MINLP model is decomposed into two levels: a master convex MINLP is solved to provide a vector of integer variables. In the second level, a continuous nonlinear problem is solved to obtain a lower bound. The approach in Guillén-Gosálbez et al. [2010] is similar: an upper level problem and a lower level problem are solved repeatedly. Integer and logic cuts are added until the bounds converge. The model in Guillén-Gosálbez and Grossmann [2010] is non-convex with a specific structure. The net present value is transferred to the $\varepsilon$-constraint. The resulting single-objective model is solved with a spatial branch-and-bound that exploits the specific structure of the model.

Pozo et al. [2012] solve their multi-objective optimization problem with an $\varepsilon$-constraint approach. They then use Principal Component Analysis (PCA) to reduce the dimensionality of the model with the objective of preserving its Pareto structure. Finally, the $\varepsilon$-constraint approach is used again on the reduced model. In Kostin et al. [2012], the $\varepsilon$-constraint is followed by the rigorous MILP dimensionality reduction approach based on the $\delta$-error definition [Guillén-Gosálbez, 2011].

In their multi-objective uncapacitated facility location problem, Xifeng et al. [2013] consider the minimization of $\mathrm{CO}_{2}$ emissions as the main objective. The economic and the service objectives are reformulated as constraints. The single-objective problem is solved with a greedy-drop heuristic.

\section{Metaheuristics for multi-objective models}

Dehghanian and Mansour [2009], Tuzkaya et al. [2011], and Zhang et al. [2013] propose Genetic Algorithms (GA) to solve their models. Tuzkaya et al. [2011] propose a two-stage methodology for the strategic design of a reverse logistics network. The weights of each criterion are calculated with an Analytic Network Process (ANP) procedure, and then the candidate locations are evaluated with a fuzzy TOPSIS (Technique for Order of Preference by Similarity to Ideal Solution). In a second stage, the facility location problem is solved by means of a genetic algorithm. In Zhang et al. [2013], the upper level searches for 
the optimal terminal network configurations by using a genetic algorithm, while the lower level performs multi-commodity flow assignment over a multimodal network. Jamshidi et al. [2012] develop a Memetic Algorithm (MA) to solve a multi-objective supply chain problem with cost and environmental issues. The Taguchi method is used to reduce the computational time in the crossover step.

Eskandarpour et al. [2013] use a parallel Variable Neighborhood Search (VNS) to solve a multiobjective reverse supply chain design problem for a post-sales service. The effectiveness of parallelization is proved by a comparison with the results of a generic VNS.

The closed-loop MILP model proposed by Devika et al. [2014] is solved through an hybrid approach combining three novel hybrid metaheuristics based on adapted imperialist competitive algorithms and variable neighborhood search. The 2-echelon location routing model proposed by Govindan et al. [2013] is solved using a hybrid metaheuristic algorithm combining the adapted multi-objective particle swarm optimization (MOPSO) and the adapted multi-objective variable neighborhood search algorithm (AMOVNS).

In order to solve their sustainable hub location problem, Mohammadi et al. [2014] model their MINLP with GAMS and solve it with the BARON software. However computing times are huge for the instances with 15 nodes. Due to this limitation, they developed a simulated annealing and an Imperialist Competitive Algorithm (ICA) to find good solutions.

\section{Multi-Criteria Decision Analysis and interactive methods}

Multi-Criteria Decision Analysis is able to handle a larger number of environmental and social criteria. Interactive methods are generally preferred when the number of objective functions increases and when the decision makers wish to be involved in the construction of a solution.

The hospital location problem described by Malczewski and Ogrycżak [1990] is solved as an illustration of an interactive approach proposed by the authors : DINA (Dynamic Interactive Network Analysis System). This method is specialized for the solution of facility location or transport problem and facilities user-system interactions for the determination of Pareto optimal solutions.

As an alternative to Analytic Hierarchy Process [Saaty, 1990], Datta [2012] develop a multi-criteria decision making process based on Reasoning Maps [Montibeller et al., 2008] to solve a rural development problem.

Pishvaee et al. [2012b] propose an interactive fuzzy solution approach based upon a credibility measure. At each iteration, a crisp bi-objective MILP is converted into a single objective model according to a dedicated aggregation function. The model is then solved by LINGO 8.0. The decision maker can then alter the main parameters of the model if the proposed solution is not satisfactory.

Alçada-Almeida et al. [2009] describe an Interactive Decision Support System (IDSS) based on goal programming and integrating techniques from the fields of atmospheric dispersion modeling, facility location and geographical information systems. The goals are the ideal solution value for each of the five objectives.

\section{Other methods and Hybrid Approaches}

Galante et al. [2010] analyze the solution space by means of goal programming, weighted sum and fuzzy multi-objective programming techniques. First, the valu of the objectives are determined via goal programming. Next, a Pareto-optimal solution between these solutions is obtained by means of weighted sum and fuzzy multi-objective programming methods. Goal programming is also used in Alçada-Almeida et al. [2009], Pati et al. [2008] and Ramudhin et al. [2010]. Quariguasi Frota Neto et al. [2008] evaluate Pareto efficiency using Data Envelopment Analysis (DEA). The model aims to minimize the necessary reduction in cost and environmental impact to eliminate efficiency. Hugo and Pistikopoulos [2005] and Zamboni et al. [2009] reformulate their multi-objective model as a multi-parametric MILP which is solved by the algorithm described in Dua and Pistikopoulos [2000]. Wang et al. [2011] use the normalized normal constraint method [Messac et al., 2013] and the subproblems are solved with IBM Ilog Cplex 9.0. 


\subsection{Modeling tools and solvers}

Faced with high complexity of the supply chains, modeling the chain network design problems is often an issue it itself. Modeling languages are often used in combination with an MIP solver. The Table 13 details the use of modeling tools and solvers in the reference papers. We distinguish the LCA-based models (column 2) for the non-LCA-based models (column 3) in order to exhibit the differences between the two branches.

\begin{tabular}{|c|c|c|}
\hline $\begin{array}{l}\text { Modeling / solver } \\
\text { tool }\end{array}$ & LCA-based models & Other models \\
\hline GAMS/CPLEX & $\begin{array}{l}\text { Guillén-Gosálbez et al. [2008], Bojarski et al. } \\
\text { [2009], Guillén-Gosálbez and Grossmann } \\
\text { [2009], Mele et al. [2009], Zamboni et al. } \\
\text { [2009], Duque et al. [2010], Guillén-Gosálbez } \\
\text { et al. [2010], Giarola et al. [2011], Mele et al. } \\
\text { [2011], Pinto-Varela et al. [2011], You and } \\
\text { Wang [2011], Zamboni et al. [2011], Abdal- } \\
\text { lah et al. [2012], Akgul et al. [2012], Giarola } \\
\text { et al. [2012a], Giarola et al. [2012b], Kostin } \\
\text { et al. [2012], Pérez-Fortes et al. [2012], Pozo } \\
\text { et al. [2012], You et al. [2012], Bernardi et al. } \\
\text { [2013], Ruiz-Femenia et al. [2013], Yue et al. } \\
\text { [2013], Mota et al. [2014], Santibañez-Aguilar } \\
\text { et al. [2014], Yue et al. [2014] }\end{array}$ & $\begin{array}{l}\text { Galante et al. [2010], Liu et al. [2011], Maru- } \\
\text { fuzzaman et al. [2014] }\end{array}$ \\
\hline GAMS/others & $\begin{array}{l}\text { Guillén-Gosálbez et al. [2008], Guillén- } \\
\text { Gosálbez and Grossmann [2009], Guillén- } \\
\text { Gosálbez and Grossmann [2010], Muñoz et al. } \\
\text { [2013], Yue et al. [2013], Yue et al. [2014] }\end{array}$ & $\begin{array}{l}\text { Papapostolou et al. [2011], Corsano et al. } \\
\text { [2011], Lira-Barragán et al. [2011], Lira- } \\
\text { Barragán et al. [2013], Mohammadi et al. } \\
{[2014]}\end{array}$ \\
\hline Lingo/Lindo & $\begin{array}{l}\text { Dehghanian and Mansour [2009], Chaabane } \\
\text { et al. [2012], Pishvaee and Razmi [2012], } \\
\text { Pishvaee et al. [2012a], Pishvaee et al. [2012b] }\end{array}$ & $\begin{array}{l}\text { Costi et al. [2004], Minciardi et al. [2008], } \\
\text { Pati et al. [2008], Harraz and Galal [2011], } \\
\text { Kannan et al. [2012], Mallidis et al. [2012], } \\
\text { Lam et al. [2013] }\end{array}$ \\
\hline AMPL/Cplex & & Berger et al. [1999] \\
\hline None/Cplex & Elia et al. [2011] & $\begin{array}{l}\text { Krikke et al. [2003], Erkut et al. [2008], Pour- } \\
\text { mohammadi et al. [2008], Ramudhin et al. } \\
\text { [2010], Chaabane et al. [2011], Wang et al. } \\
\text { [2011], Elhedhli and Merrick [2012], Elia et al. } \\
\text { [2012], Amin and Zhang [2013], Bouzembrak } \\
\text { et al. [2013], Diabat et al. [2013], Verma et al. } \\
\text { [2013], Baud-Lavigne et al. [2014], Elia et al. } \\
\text { [2014] }\end{array}$ \\
\hline None/Excel & & Krikke [2011] \\
\hline
\end{tabular}

Table 13: Use of modeling tools and solvers

The table shows that almost all LCA-based approaches use a modeling tools combined with a solver (GAMS/Cplex or Lingo/Lindo are the most popular combinations). This suggests the main difficulty in these problems is the modeling of the processes and their environmental burden. In contrast, usual optimization methods can solve the model to optimality, although sometimes with a very long calculation time. On the contrary, non-LCA models are generally more simple to express and do not always require using modeling tools.

The solvers can be used to solve either single-objective or multi-objective models with the weighted sum or $\varepsilon$-constraint techniques. However, they are not always used to solve the whole optimization model. Dehghanian and Mansour [2009] use Lindo to solve single objective models considering each objective separately in order to find the ideal point. Mallidis et al. [2012] minimize the economic objective, or the GHG emissions, or the particulate matter. Pourmohammadi et al. [2008] use Cplex to solve an LP subproblem once the facilities have been set by a genetic algorithm.

The other solvers are generally non-linear programming solvers, which include DICOPT [Guillén- 
Gosálbez et al., 2008, Guillén-Gosálbez and Grossmann, 2009, Yue et al., 2013, Corsano et al., 2011, Lira-Barragán et al., 2011, Lira-Barragán et al., 2013], SBB [Yue et al., 2013, Muñoz et al., 2013], BARON Yue et al. [2013, 2014], Mohammadi et al. [2014] CONOPT [Guillén-Gosálbez et al., 2008, Guillén-Gosálbez and Grossmann, 2010] and SNOPT [Guillén-Gosálbez and Grossmann, 2009].

\subsection{Conclusion}

In conclusion to this section, many generic or specific solution techniques have been used to solve the complex and usually large size SCND models analyzed in this review. Many problems are solved using modeling tools such as GAMS, Lingo or AMPL and linear or non-linear programming solvers. Single objective models are often modeled as MIPs and solved with standard solvers. To the opposite, a large variety of techniques have been proposed for solving multi-objective models, including MIP techniques again, but also metaheuristic approaches and hybrid exact/metaheuristic methods. Interactive and scenario analysis methods involving the decision maker's expertise are often called for. In the future, we can still expect further use of standard solvers to handle real-life problems, but solvers will probably not be able to solve all rich problems such as sustainable location routing problems. Moreover, we observe a contradictory situation: most papers report huge calculation effort in seeking optimal solutions to problems that contain much uncertainty or aggregated data. Obtaining good quality robust solutions within limited computation time would probably enable better interaction with the decision makers. There is a real need for developing efficient solution technique methods for large complex problems involving uncertainty, as well as the development of robust multi-criteria heuristic methods.

\section{Applications}

Most published papers on sustainable SCND are based upon specific applications or an industrial context. Indeed, the study of sustainable development problems emerged from real-life concerns and the modeling of environmental or social factors generally requires the description of a specific context and depends of a particular case. Few papers propose generic models not based upon a specific application or sector, but that can apply to different contexts and address fundamental questions for the supply chain design. In classical approaches of SCND or reverse logistics, we indeed observe a much larger proportion of generic models compared to sector specific rich models. Analyzing, modeling and solving supply chain design problems integrating environmental or social factors is much more complex and makes it difficult to design generic models without a specific case in mind.

The goals of this section are to classify and discuss the published works according to their application area or economic sector, types of problems and type of experiments. In doing so, we want to identify what are the leading sectors of application on which research on sustainable SCND has been focused, what are the reasons for that and to investigate possible differences between sectors and the reasons for that. We wish to address these questions in view of the analysis conducted in the previous sections, and investigate if sectorial approaches differ in environmental and social factors considered and their assessment methods, analyze the types of models and solution techniques used and what is the influence of including environmental and social aspects in the network design in these sectors.

It is also of interest to discuss the kind of experiments that have been conducted order to validate or apply the models and solution techniques developed for a given problem. Likewise for other supply chain design or optimization problems in general, we found two different experimental approaches in the reviewed papers : papers based upon empirical data, that are based on real data arising from one or several companies, and papers pertaining to an industrial context, that are inspired from a realistic context. To some extent, this latter category may address problems in a more generic way than the former one. 
In addition to generic papers, the papers which we have reviewed belong to six main application sectors. Figure 7 indicates the classification of these papers according to these sectors and the type of experiments conducted (either from empirical data or from an industrial context).

As can be seen, most papers in Figure 7 use empirical data and are based on real applications. Also one can observe that a few economic sectors related to the process industries (biomass-to-bioenergy, chemical processes) or waste management concentrate about half of the research. This is probably due to the great impact of these activities in environmental factors, both regarding energy consumption and pollution generation. These industries are probably those with the greatest maturity on these topics, while sectors related to the production and distribution of industrial and consumer goods are still mainly focused on the economic factors.

\subsection{Intersectorial analysis}

We can see than generic models rarely resort to LCA-based assessment but mostly for partial assessment based on the GHG emissions. W e explain this because using LCA requires a very detailed analysis of product and activity which is difficult for a generic approach. Besides, evaluating GHG emissions is a fairly straightforward method and results in formulae that can be easily incorporated into a mathematical model. Indeed we observe that LCA is used for a majority of papers in the bio-energy and chemical processes sectors, but also for consumer and industrial goods sectors. This is understandable because the concerned works are very specific, which allows using LCA.

Regarding the explicit inclusion of the social dimension into the models, we did not identify reasons explaining that the social factors are considered or not for a given sector of application and actually the public sector paper considers the economic and social factors only, but concerns a very specific study.

Consistently with the analysis of Section 5, we could not find any correlation between the type of models used and the sector of application. We believe that the use of a linear or non-linear formulation with a deterministic or stochastic context is more linked to the technical specificity of the problem studied than to the economic sector. Indeed advanced modeling calls for the inclusion of a multi-objective and a stochastic approach rather than a deterministic one, whatever the considered sector. Moreover, we did not find any correlation between these approaches and the fact that the models are generic or applied to a given sector. The choice of approach depends more on the complexity of the problem and size of experimental data.

\subsection{Conclusion on applications}

In summary to this section, we have observed that the research on quantitative optimization models for sustainable SCND problems covers a wide variety of areas and specific applications, while only a few works only are devoted to the study of generic sustainable SCND problems. Process industry sectors such as energy and chemical processes as well as waste management concentrate more than half of the works, while the rest is concentrated on the analysis of consumer and industrial goods problem, the public sector and generic problems. The specificity of supply chains in different areas, especially for the assessment of environmental factors makes it very difficult to develop generic models that would remain realistic enough. But this should be a goal for the future.

Sustainable SCND problems for biomass-to-bioenergy, chemical processes or waste management are already well studied due to the importance of environmental factors (mainly energy consumption and pollution), but should be further investigated. To the contrary, industrial and consumer goods sectors are well studied in some areas such as tires, steel and aluminum, paper, glass and containers, as well as medical items, and white goods. But surprisingly enough, areas like manufacturing in general, aeronautics and the automotive industry, transportation services, retail and food distribution have hardly been studied, although they are well present in the research on SCND in general. Extending research on SCND by 


\section{Biomass to bioenergy}

Mele et al. [2009], Giarola et al. [2011], You and Wang [2011], Akgul et al. [2012], Elia et al. [2011], Papapostolou et al. [2011], Elia et al. [2012], Giarola et al. [2012a,b], Kostin et al. [2012], Pérez-Fortes et al. [2012], You et al. [2012], Zamboni et al. [2011, 2009], Mele et al. [2011], Bernardi et al. [2013], Lam et al. [2013], Yue et al. [2013], Elia et al. [2014], Marufuzzaman et al. [2014], Santibañez-Aguilar et al. [2014], Yue et al. [2014]

Guillén-Gosálbez et al. [2010], Corsano et al. [2011]

\section{Chemical processes}

Hugo et al. [2005], Guillén-Gosálbez et al. [2008], Bojarski et al. [2009], Guillén-Gosálbez and Grossmann [2009, 2010], Pozo et al. [2012], Ruiz-Femenia et al. [2013]

Hugo and Pistikopoulos [2005], Guillén-Gosálbez and Grossmann [2010], Liu et al. [2011]

\section{Waste management}

Caruso et al. [1993], Bloemhof-Ruwaard et al. [1996], Berger et al. [1999], Costi et al. [2004], Erkut et al. [2008], Minciardi et al. [2008], Alçada-Almeida et al. [2009], Duque et al. [2010], Galante et al. [2010], Bouzembrak et al. [2013], Lam et al. [2013]

\section{Industrial Goods}

Dehghanian and Mansour [2009], Ramudhin et al. [2010],

Chaabane et al. [2011], Kannan et al. [2012], Kanzian et al. [2013], Zhang et al. [2013], Mota et al. [2014]

Pati et al. [2008], Pourmohammadi et al. [2008], Quariguasi Frota Neto et al. [2008], Pinto-Varela et al. [2011], Chaabane et al. [2012]

\section{Consumer goods}

Krikke et al. [2003], Harraz and Galal [2011], Krikke [2011], Tuzkaya et al. [2011], Abdallah et al. [2012], Mallidis et al. [2012], Pishvaee and Razmi [2012], PishDiabat et al. [2013], Eskandarpour et al. [2013], vaee et al. [2012a,b], Sadrnia et al. [2013], Devika et al. [2014]

\section{Public sector}

Beheshtifar and Alimoahmmadi [2014], Datta [2012],

Malczewski and Ogrycżak [1990], Verma et al. [2013]

Figure 6: Review of industrial applications 
explicitly incorporating the environmental and social dimensions, should be a fruitful area of research. Finally, applications regarding the public sector have been limited so far and provide a great potential for the consideration of both the environmental and social dimensions of sustainable development.

\section{General conclusions and research directions}

\subsection{Summary of findings and contributions}

The broad field of supply chain management has become an essential domain with the globalization and the constant search for competitiveness. Simultaneously, the growing consideration for sustainable development has led private and public actors to integrate the three pillars of sustainability within their management. At the strategic level, the design or re-engineering of supply chain networks is a key issue, centered around questions of locating and sizing facilities and defining material flows trough the network. Optimization techniques have always been a key tool for addressing these problems. The consideration of sustainable development factors within the network design problem has indeed been the subject of many works since the publication of the Bruntland Report. These were our motivations for proposing this review of the literature focused on optimization models and techniques on supply chain network design problems integrating sustainable development factors, for which no previous review had been published. The overall justification of research in this area can be summarized by the observation that the consideration of sustainable development factors may have a significant impact on the design and configuration of the supply chain, as illustrated by the case study in You and Wang [2011].

Amidst the many works on closely related areas to sustainable SCND problems, we decided to limited our analysis to works relying on mathematical optimization models, and integrating explicitly at least two of the three dimensions of sustainable development in the objective function(s) or the constraints. We therefore excluded papers focused on only one of the dimensions or on closely related areas such as reverse logistics or undesirable facility location when they only addressed sustainable development implicitly. Besides, fields like reverse logistics or facility locations have been the subject of many previous reviews.

Within our literature survey, we have addressed the four questions stated in the Introduction, (i) which environmental and social criteria are considered in sustainable SCND research? (ii) how are they integrated into mathematical models? (iii) which optimization methods and tools are used? (iv) which real-life applications of sustainable SCND are described in the scientific literature?

We summarize our findings below and point out a number of research directions for the future in the following sub section. The global contribution of our work has been to identify, to our best knowledge, classify and analyze all the published literature within the scope of survey and determine key factors of these works as well as identify future directions. We have indeed identified 87 papers published in 41 international peer-reviewed journals, among which 10 addressed simultaneously the three dimensions of sustainable development, 74 the economic and environmental factors and only 3 were focused on both the economic and social dimensions, while no work integrates the environmental and social factors only. We have identified that a majority of the works were focused on specific areas of applications, while only some of the published papers addressed generic sustainable SCND models. The major contribution of our work has been to analyze and compare the research works and determine their key characteristics: methodologies used for environmental assessment, factors retained for integrating social dimension, mathematical modeling approaches and solution methods developed, as well as the applications developed in different sectors and types of experiment conducted with these models.

As mentioned above, we identified that a large majority of the works focus on the economic and environmental factors. In contrast, social aspects of sustainable development are rarely considered in quantitative studies in comparison with environmental issues and even less research addresses all three dimensions together. Furthermore, there are a limited number of sub-factors of the three main dimensions 
considered in published studies. The consideration of environmental factors is often limited to GHG emissions or energy consumption, or the consideration of social factors is often limited to evaluation of jobs created or respect of working legislation. The many possible factors proposed by specialized works such as Chardine-Baumann and Botta-Genoulaz [2014] are far from being considered. Regarding environmental factors, several performance measures have been considered to tackle environmental impacts, especially for proposing analytic measures for GHG emissions or their global cost impact. These are the principal factors used in quantitative models. Simultaneously, we observed that LCA is the dominant approach to incorporate environmental issues in SCND, but all impact categories are not considered in general.

In contrast, the lack of published research addressing social factors together with other dimensions appears to be due to the difficulty of modeling such factors. Social factors are sometimes considered indirectly within the evaluation of economic and environmental factors. Hence, research that is able to find a balance between supply chain costs and the broad spectrum of impact categories remains largely an uncharted territory to date. Still the models reviewed are from integrating the characteristics of the ISO 26000 norm.

Regarding modeling techniques, research concentrates on the development of deterministic MILP models solved with standard modeling tools and solvers. This is due to the ability of these modeling techniques to integrate environmental or social aspects in complex industrial process for each particular sector. Performance of state-of-the-art solvers allows solving real-life instances even though very long computing time are sometimes reported. Developing advanced heuristic solution techniques for solving large-sized problems efficiently seems yet to be difficult because of the complexity of these types of problems. Indeed few works use heuristic or metaheuristic approaches.

Although uncertainty is often an intrinsic characteristic of the studied problems, most authors still use deterministic models. One main reason is that large stochastic models would be intractable whereas deterministic models can be solved by state-of-the-art solvers. Because of the characteristics of the addressed problems, some of the works consider non-linear models and call for specific solution techniques or non-linear solvers.

Sustainable SCND problems are multi-objective by nature and the models that we have studied consider at least two dimensions in the objective function or constraints and sometimes several subfactors. However about one third of the proposed models are limited to a single aggregated objective, while two thirds explicitly consider several objective functions. In terms of solution techniques, however, a large majority of papers are limited to the use of a weighted sum of objectives or the $\varepsilon$-constraint approach with minimization of an economic criterion and an environmental criterion expressed as a constraint. However a significant number of works call for available multi-objective solution techniques such as goal programming or metaheuristics. We identified a significant lack of studies on truly multiobjective approaches with adequate consideration of uncertainties and risks (see Heckmann et al. [2015] for a review on supply chain risk).

In terms of applications, besides the proposition of generic models, a strong emphasis is made on process industries (biofuel, chemical processes) and on waste management problems. Such works account to about half of the published works devoted to specific applications. We can argue that the upstream part of a supply chain is often where greatest environmental impact arises and so this focus makes sense. However these applications reflect highly integrated, often automated processes, whereas supply chains in the industrial or consumer goods areas are often decentralized and involve more uncertainty due to human factors. It is noteworthy to remark that many sectors (automotive industry, distribution of consumer products and transport) have not yet or little been considered.

\subsection{Research avenues}

These findings lead us to suggest some directions for future theoretical and applied research works to fill the gaps found in the literature of sustainable SCND. Some of the possible future directions are however 
direct consequences of the analysis of the preceding paragraphs and will not be repeated here.

Regarding the environmental dimension, it is worthy to consider GHG emissions relative to nodes (facilities) and arcs (transport links) of the supply chain network together with other performance measures such as waste generation or energy consumption. In other words, optimizing only one criteria does not allow the minimization of overall environmental impact. Classical process-based LCA is the most frequently used method to assess the environmental impacts. But employing this approach is sometimes difficult for practical reasons. Besides, LCA pays a greater attention to the early stages of the life-cycle of a new product development which is often before the supply chain network has been designed. Therefore, developing novel approaches combining Input-Output LCA (such as material flow analysis) and processbased approaches may better consider environmental damage throughout the entire product life-cycle. Carbon credit exchange schemes (despite their current limitations) could be also be more widely considered at the strategic decision level together with efforts to reduce the GHG emissions within the supply chain.

Social aspects should be given more attention in future research to achieve a sustainable SCND. However, developing methodologies for quantifying the social aspects is a challenging task. Their consideration at the stage of scenarios definition before optimization may remain an effective alternative within a decision making process. A real challenge is probably to define the scope for the social impact to consider. Contrary to environmental studies (and more especially LCA based approaches), this question is never discussed in the papers we found addressing the social dimension. This results in very disparate metrics, with a relative dominance of metrics concerning employment and health impacts. The generalization of LCA to the social dimension is known as social LCA (or S-LCA). Its goal is to deliver decision-making support related to the social impacts of products or systems (see the reviews by Jorgensen [2013] and Jorgensen et al. [2008]). S-LCA was not used in our reference papers. This is a serious track to better integrate social dimension into quantitative models. Recent developments have led the definition of the ISO 26000 norm on social responsibility. However, due to its recent publication, there is still no research on the impact of this standard on supply-chain practices [Castka and Balzarova, 2008, Hahn, 2013]. This seems another fruitful research avenue.

As already mentioned, sustainable development problems are clearly multi-objective problems. They cannot be expressed with a single dimension unless all factors are reduced to their cost equivalent. Alternatively, a model focused on economic optimization has to consider explicit environmental or social factors as constraints. Still very few published models handle the economic, environmental and social dimensions simultaneously. This calls for the development of efficient multi-objective models and dimensionality reduction techniques that adequately address the different dimensions of sustainable development. Uncertainty and risk should also be better considered in sustainable SCND. In real problems, uncertainty is present in many estimated factors: demand level, impact assessment, costs, social impacts, etc. The consideration of realistic management features such as supplier selection and risk management have been frequently considered in supply chain and procurement research, but quantitative sustainable SCND models incorporating these features are still scarce.

Strategic decisions such as network design have a significant influence on tactical and operational constraints and decisions. However, the coordination of the different levels has been almost ignored in the sustainable SCND literature. More attention should be given to integrated strategic and tactical models. Tactical decisions may have significant impacts on costs and impacts for example changes in delivery frequencies improve customer satisfaction but impact on vehicle fill rates and therefore efficiency of transport.

Up to now, the literature concentrates on specific rich models focused on a particular real-life application. For general industrial companies, there is a need to develop generic models for sustainable SCND, such as in classical works on SCND. Generic models should include features such as multiple commodities, bill of materials, multi-layer supply chains and multiple periods. Assumptions such as capacity expansion and technology levels also deserve future research. Environmental impact should be 
measured at all steps in the supply chain. For example GHG emissions should be considered at nodes (production or storage facilities) and on the arcs (transport activities and the modes used). Studies that consider social dimension use a large variety of assessment metrics and are all based on empirical case studies. This shows that we are not close to having generic models including the three dimensions of sustainable development.

When it comes to solution techniques, standard (but powerful) solvers have been the most widely used tools to solve the resulting models in sustainable SCND. However, the size and particularly the number of binary variables in practical SCND problems raises difficulties for solving them in a reasonable amount of time. This issue is even more crucial for adequately solving non-linear, stochastic or multi-objective models. The capability of solvers practically restricts the scope of most studies. Therefore, developing efficient exact or heuristic solution methods is a real need for the future, especially for solving extension of SCND problems (e.g. location-routing problems).

Government legislation and customers' awareness are among main reasons that prompt companies or organizations to pay an increased attention to environmental and social impacts of their activities. Many major companies concentrate on their core business and outsource a large of their production or distribution activities to subcontractors, distributors, third party logistics providers. Thus, sustainable development goals can indeed be truly achieved only by considering the supply chain as a complex system with collaborating stakeholders (government, consumers and multiple companies) which address the life-cycle perspectives together.

Finally, many challenging problems and solution methods have been published separately by authors within the management, industrial engineering or operations research literature. For example, we observed that all LCA-based approaches use standard solvers which seek optimal solutions to models that include much uncertainty. On the other hand, many operational researchers sometimes use very sophisticated algorithms to solve problems with poor environmental or economic modeling. Solving rich environmental SCND models to optimality within acceptable time is still beyond the capabilities of current mathematical solvers. Thus, collaboration between researchers from various communities would result in realistic modeling of the real-life and efficient near optimal solution methods to solve the optimization problems.

\section{Reference Papers}

T. Abdallah, A. Farhat, A. Diabat, and S. Kennedy. Green supply chains with carbon trading and environmental sourcing: formulation and life cycle assessment. Applied Mathematical Modelling, 36(9): 4271-4285, 2012.

T. Abdallah, A. Diabat, and J. Rigter. Investigating the option of installing small scale PVs on facility rooftops in a green supply chain. International Journal of Production Economics, 146(2):465-477, 2013.

O. Akgul, N. Shah, and L. G. Papageorgiou. An optimisation framework for a hybrid first/second generation bioethanol supply chain. Computers \& Chemical Engineering, 42(0):101-114, 2012.

L. Alçada-Almeida, J. Coutinho-Rodrigues, and J. Current. A multiobjective modeling approach to locating incinerators. Socio-Economic Planning Sciences, 43(2):111-120, 2009.

S. H. Amin and G. Zhang. A multi-objective facility location model for closed-loop supply chain network under uncertain demand and return. Applied Mathematical Modelling, 37(6):4165-4176, 2013.

B. Baud-Lavigne, B. Agard, and B. Penz. Environmental constraints in joint product and supply chain design optimization. Computers and Industrial Engineering, 76(0):16-22, 2014. 
S. Beheshtifar and A. Alimoahmmadi. A multiobjective optimization approach for location-allocation of clinics. International Transactions in Operational Research, pages n/a-n/a, 2014. doi: 10.1111/itor. 12088.

C. Berger, G. Savard, and A. Wizere. EUGENE: an optimization model for integrated regional solid waste management planning. International Journal of Environment and Pollution, 12(2-3):280-307, 1999.

A. Bernardi, S. Giarola, and F. Bezzo. Spatially explicit multiobjective optimization for the strategic design of first and second generation biorefineries including carbon and water footprints. Industrial 8 Engineering Chemistry Research, 52(22):7170-7180, 2013.

J. Bloemhof-Ruwaard, L. Van Wassenhove, H. Gabel, and P. Weaver. An environmental life cycle optimization model for the European pulp and paper industry. Omega, 24(6):615-629, 1996.

A. Bojarski, J. Laínez, A. Espuña, and L. Puigjaner. Incorporating environmental impacts and regulations in a holistic supply chains modeling: An lca approach. Computers and Chemical Engineering, 33(10): 1747-1759, 2009.

Y. Bouzembrak, H. Allaoui, G. Goncalves, and H. Bouchriha. A multi-modal supply chain network design for recycling waterway sediments. International Journal of Environment and Pollution, 51(1):15-31, 2013.

C. Caruso, A. Colorni, and M. Paruccini. The regional urban solid waste management system: A modelling approach. European Journal of Operational Research, 70(1):16-30, 1993.

A. Chaabane, A. Ramudhin, and M. Paquet. Designing supply chains with sustainability considerations. Production Planning \& Control, 22(8):727-741, 2011. doi: 10.1080/09537287.2010.543554.

A. Chaabane, A. Ramudhin, and M. Paquet. Design of sustainable supply chains under the emission trading scheme. International Journal of Production Economics, 135(1):37-49, 2012.

G. Corsano, A. Vecchietti, and J. Montagna. Optimal design for sustainable bioethanol supply chain considering detailed plant performance model. Computers \& Chemical Engineering, 35(8, SI):13841398, 2011.

P. Costi, R. Minciardi, M. Robba, M. Rovatti, and R. Sacile. An environmentally sustainable decision model for urban solid waste management. Waste Management, 24(3):277-295, 2004.

S. Datta. Multi-criteria multi-facility location in niwai block, rajasthan. IIMB Management Review, 24 (1):16-27, 2012 .

F. Dehghanian and S. Mansour. Designing sustainable recovery network of end-of-life products using genetic algorithm. Resources, Conservation and Recycling, 53(10):559-570, 2009.

K. Devika, A. Jafarian, and V. Nourbakhsh. Designing a sustainable closed-loop supply chain network based on triple bottom line approach: A comparison of metaheuristics hybridization techniques. European Journal of Operational Research, 235(3):594-615, 2014.

A. Diabat, T. Abdallah, A. Al-Refaie, D. Svetinovic, and K. Govindan. Strategic closed-loop facility location problem with carbon market trading. IEEE Transactions on Engineering Management, 60(2): 398-408, 2013. 
J. Duque, A. Barbosa-Povoa, and A. Novais. Design and planning of sustainable industrial networks: Application to a recovery network of residual products. Industrial \&3 Engineering Chemistry Research, 49(9):4230-4248, 2010.

S. Elhedhli and R. Merrick. Green supply chain network design to reduce carbon emissions. Transportation Research Part D: Transport and Environment, 17(5):370-379, 2012.

J. Elia, R. Baliban, X. Xiao, and C. Floudas. Optimal energy supply network determination and life cycle analysis for hybrid coal, biomass, and natural gas to liquid (CBGTL) plants using carbon-based hydrogen production. Computers \&3 Chemical Engineering, 35(8):1399-1430, 2011.

J. A. Elia, R. C. Baliban, and C. A. Floudas. Nationwide energy supply chain analysis for hybrid feedstock processes with significant co2 emissions reduction. AIChE Journal, 58(7):2142-2154, 2012. ISSN 1547-5905. doi: 10.1002/aic.13842. URL http://dx.doi.org/10.1002/aic.13842.

J. A. Elia, R. C. Baliban, and C. A. Floudas. Nationwide, regional, and statewide energy supply chain optimization for natural gas to liquid transportation fuel (GTL) systems. Industrial \& Engineering Chemistry Research, 53(13):5366-5397, 2014.

E. Erkut, A. Karagiannidis, G. Perkoulidis, and S. A. Tjandra. A multicriteria facility location model for municipal solid waste management in north greece. European Journal of Operational Research, 187 (3):1402-1421, 2008.

M. Eskandarpour, S. Zegordi, and E. Nikbakhsh. A parallel variable neighborhood search for the multiobjective sustainable post-sales network design problem. International Journal of Production Economics, 145(1):117-131, 2013.

G. Galante, G. Aiello, M. Enea, and E. Panascia. A multi-objective approach to solid waste management. Waste Management, 30(8-9):1720-1728, 2010.

S. Giarola, A. Zamboni, and F. Bezzo. Spatially explicit multi-objective optimisation for design and planning of hybrid first and second generation biorefineries. Computers \& Chemical Engineering, 35 (9):1782-1797, 2011.

S. Giarola, N. Shah, and F. Bezzo. A comprehensive approach to the design of ethanol supply chains including carbon trading effects. Bioresource Technology, 107:175-185, 2012a.

S. Giarola, A. Zamboni, and F. Bezzo. Environmentally conscious capacity planning and technology selection for bioethanol supply chains. Renewable Energy, 43:61-72, 2012b.

K. Govindan, A. Jafarian, R. Khodaverdi, and K. Devika. Two-echelon multiple-vehicle location-routing problem with time windows for optimization of sustainable supply chain network of perishable food. International Journal of Production Economics, In Press, 2013.

G. Guillén-Gosálbez and I. Grossmann. Optimal design and planning of sustainable chemical supply chains under uncertainty. AICHE Journal, 55(1):99-121, 2009.

G. Guillén-Gosálbez and I. Grossmann. A global optimization strategy for the environmentally conscious design of chemical supply chains under uncertainty in the damage assessment model. Computers 83 Chemical Engineering, 34(1):42-58, 2010.

G. Guillén-Gosálbez, J. Caballero, and L. Jiménez. Application of life cycle assessment to the structural optimization of process flowsheets. Industrial \& Engineering Chemistry Research, 47(3):777-789, 2008. 
G. Guillén-Gosálbez, F. Mele, and I. Grossmann. A bi-criterion optimization approach for the design and planning of hydrogen supply chains for vehicle use. AICHE Journal, 56(3):650-667, 2010.

N. A. Harraz and N. M. Galal. Design of sustainable end-of-life vehicle recovery network in Egypt. Ain Shams Engineering Journal, 2(3-4):211-219, 2011.

I. Harris, M. Naim, A. Palmer, A. Potter, and C. Mumford. Assessing the impact of cost optimization based on infrastructure modelling on $\mathrm{CO}_{2}$ emissions. International Journal of Production Economics, 131(1):313-321, 2011.

A. Hugo and E. Pistikopoulos. Environmentally conscious long-range planning and design of supply chain networks. Journal of Cleaner Production, 13(15):1471-1491, 2005.

A. Hugo, P. Rutter, S. Pistikopoulos, A. Amorelli, and G. Zoia. Hydrogen infrastructure strategic planning using multi-objective optimization. International Journal of Hydrogen Energy, 30(15):1523-1534, 2005.

R. Jamshidi, S. Fatemi Ghomi, and B. Karimi. Multi-objective green supply chain optimization with a new hybrid memetic algorithm using the taguchi method. Scientia Iranica, 19(6):1876-1886, 2012.

D. Kannan, A. Diabat, M. Alrefaei, K. Govindan, and G. Yong. A carbon footprint based reverse logistics network design model. Resources, Conservation and Recycling, 67(0):75-79, 2012.

C. Kanzian, M. Kühmaier, J. Zazgornik, and K. Stampfer. Design of forest energy supply networks using multi-objective optimization. Biomass and Bioenergy, 58(0):294-302, 2013.

A. Kostin, G. Guillén-Gosálbez, F. Mele, and L. Jiménez. Identifying key life cycle assessment metrics in the multiobjective design of bioethanol supply chains using a rigorous mixed-integer linear programming approach. Industrial 6 Engineering Chemistry Research, 51(14):5282-5291, 2012.

H. Krikke. Impact of closed-loop network configurations on carbon footprints: A case study in copiers. Resources, Conservation and Recycling, 55(12):1196-1205, 2011.

H. Krikke, J. Bloemhof-Ruwaard, and L. N. Van Wassenhove. Concurrent product and closed-loop supply chain design with an application to refrigerators. International Journal of Production Research, 41(16): 3689-3719, 2003.

H. Lam, W. Wendy Ng, R. Ng, E. Ng, M. K. Abdul Aziz, and D. Ng. Green strategy for sustainable waste-to-energy supply chain. Energy, 57(0):4-16, 2013.

L. F. Lira-Barragán, J. M. Ponce-Ortega, M. Serna-González, and M. M. El-Halwagi. An MINLP model for the optimal location of a new industrial plant with simultaneous consideration of economic and environmental criteria. Industrial \&5 Engineering Chemistry Research, 50(2):953-964, 2011.

L. F. Lira-Barragán, J. M. Ponce-Ortega, F. Nápoles-Rivera, M. Serna-González, and M. M. El-Halwagi. Incorporating property-based water networks and surrounding watersheds in site selection of industrial facilities. Industrial \& Engineering Chemistry Research, 52(1):91-107, 2013.

P. Liu, A. Whitaker, E. N. Pistikopoulos, and Z. Li. A mixed-integer programming approach to strategic planning of chemical centres: A case study in the UK. Computers \& Chemical Engineering, 35(8): 1359-1373, 2011.

J. Malczewski and W. Ogrycżak. An interactive approach to the central facility location problem: locating pediatric hospitals in Warsaw. Geographical Analysis, 22(3):244-258, 1990. 
I. Mallidis, R. Dekker, and D. Vlachos. The impact of greening on supply chain design and cost: a case for a developing region. Journal of Transport Geography, 22:118-128, 2012.

M. Marufuzzaman, S. D. Ek, sioğlu, and R. Hernandez. Environmentally friendly supply chain planning and design for biodiesel production via wastewater sludge. Transportation Science, 48(4):555-574, 2014.

F. Mele, G. Guillén-Gosálbez, and L. Jimenez. Optimal planning of supply chains for bioethanol and sugar production with economic and environmental concerns. In J. Jezowski and J. Thullie, editors, 19th European Symposium on Computer Aided Process Engineering, volume 26, pages 997-1002. Elsevier, 2009 .

F. Mele, A. Kostin, G. Guillén-Gosálbez, and L. Jiménez. Multiobjective model for more sustainable fuel supply chains. a case study of the sugar cane industry in argentina. Industrial $\&$ Engineering Chemistry Research, 50(9):4939-4958, 2011.

R. Minciardi, M. Paolucci, M. Robba, and R. Sacile. Multi-objective optimization of solid waste flows: Environmentally sustainable strategies for municipalities. Waste Management, 28(11):2202-2212, 2008.

M. Mohammadi, S. Torabi, and R. Tavakkoli-Moghaddam. Sustainable hub location under mixed uncertainty. Transportation Research Part E: Logistics and Transportation Review, 62(0):89-115, 2014.

B. Mota, M. I. Gomes, A. Carvalho, and A. P. Barbosa-Povoa. Towards supply chain sustainability: economic, environmental and social design and planning. Journal of Cleaner Production, -(in press):-, 2014. doi: http://dx.doi.org/10.1016/j.jclepro.2014.07.052.

E. Muñoz, E. Capón-García, J. Laínez, A. Espuña, and L. Puigjaner. Considering environmental assessment in an ontological framework for enterprise sustainability. Journal of Cleaner Production, 47: 149-164, 2013.

C. Papapostolou, E. Kondili, and J. Kaldellis. Development and implementation of an optimisation model for biofuels supply chain. Energy, 36(10):6019-6026, 2011.

R. Pati, P. Vrat, and P. Kumar. A goal programming model for paper recycling system. Omega, 36(3): 405-417, 2008.

M. Pérez-Fortes, J. Laínez-Aguirre, P. Arranz-Piera, E. Velo, and L. Puigjaner. Design of regional and sustainable bio-based networks for electricity generation using a multi-objective milp approach. Energy, 44(1):79-95, 2012.

T. Pinto-Varela, A. Barbosa-Póvoa, and A. Novais. Bi-objective optimization approach to the design and planning of supply chains: Economic versus environmental performances. Computers \& Chemical Engineering, 35(8):1454-1468, 2011.

M. Pishvaee and J. Razmi. Environmental supply chain network design using multi-objective fuzzy mathematical programming. Applied Mathematical Modelling, 36(8):3433-3446, 2012.

M. Pishvaee, J. Razmi, and S. Torabi. Robust possibilistic programming for socially responsible supply chain network design: A new approach. Fuzzy Sets and Systems, 206(0):1-20, 2012a.

M. Pishvaee, S. Torabi, and J. Razmi. Credibility-based fuzzy mathematical programming model for green logistics design under uncertainty. Computers and Industrial Engineering, 62(2):624-632, 2012b. 
H. Pourmohammadi, M. Rahimi, and M. Dessouky. Sustainable reverse logistics for distribution of industrial waste/byproducts: A joint optimization of operation and environmental costs. Supply Chain Forum: an International Journal, 9(1):2-17, 2008.

C. Pozo, R. Ruiz-Femenia, J. Caballero, G. Guillén-Gosálbez, and L. Jimenez. On the use of principal component analysis for reducing the number of environmental objectives in multi-objective optimization: Application to the design of chemical supply chains. Chemical EngineeringScience, 69(1):146-158, 2012.

J. Quariguasi Frota Neto, J. Bloemhof-Ruwaard, J. van Nunen, and E. van Heck. Designing and evaluating sustainable logistics networks. International Journal of Production Economics, 111(2):195-208, 2008.

A. Ramudhin, A. Chaabane, and M. Paquet. Carbon market sensitive sustainable supply chain network design. International Journal of Management Science and Engineering Management, 5(1):30-38, 2010.

R. Ruiz-Femenia, G. Guillén-Gosálbez, L. Jiménez, and J. Caballero. Multi-objective optimization of environmentally conscious chemical supply chains under demand uncertainty. Chemical Engineering Science, 95:1-11, 2013.

A. Sadrnia, N. Ismail, N. Zulkifli, M. K. A. Ariffin, H. Nezamabadi-pour, and H. Mirabi. A multiobjective optimization model in automotive supply chain networks. Mathematical Problems in Engineering, 2013 (Article ID 823876):10 pages, 2013.

M. M. Saffar, H. G. Shakouri, and J. Razmi. A new bi-objective mixed integer linear programming for designing a supply chain considering co2 emission. Uncertain Supply Chain Management, 2(4):275-292, 2014 .

M. M. Saffar, H. G. Shakouri, and J. Razmi. A new multi objective optimization model for designing a green supply chain network under uncertainty. International Journal of Industrial Engineering Computations, 6(1):15-32, 2015.

J. E. Santibañez-Aguilar, J. B. González-Campos, J. M. Ponce-Ortega, M. Serna-González, and M. M. El-Halwagi. Optimal planning and site selection for distributed multiproduct biorefineries involving economic, environmental and social objectives. Journal of Cleaner Production, 65(0):270-294, 2014.

G. Tuzkaya, B. Gülsün, and S. Önsel. A methodology for the strategic design of reverse logistics networks and its application in the Turkish white goods industry. International Journal of Production Research, 49(15):4543-4571, 2011.

M. Verma, M. Gendreau, and G. Laporte. Optimal location and capability of oil-spill response facilities for the south coast of Newfoundland. Omega, 41(5):856-867, 2013.

F. Wang, X. Lai, and N. Shi. A multi-objective optimization for green supply chain network design. Decision Support Systems, 51(2):262-269, 2011.

T. Xifeng, Z. Ji, and X. Peng. A multi-objective optimization model for sustainable logistics facility location. Transportation Research Part D: Transport and Environment, 22:45-48, 2013.

F. You and B. Wang. Life cycle optimization of biomass-to-liquid supply chains with distributed centralized processing networks. Industrial and Engineering Chemistry Research, 50:10102-10127, 2011.

F. You, L. Tao, D. Graziano, and S. Snyder. Optimal design of sustainable cellulosic biofuel supply chains: Multiobjective optimization coupled with life cycle assessment and input-output analysis. AIChE Journal, 58(4):1157-1180, 2012. 
D. Yue, M. A. Kim, and F. You. Design of sustainable product systems and supply chains with life cycle optimization based on functional unit: General modeling framework, mixed-integer nonlinear programming algorithms and case study on hydrocarbon biofuels. ACS Sustainable Chemistry 83 Engineering, 1(8):1003-1014, 2013.

D. Yue, M. Slivinsky, J. Sumpter, and F. You. Sustainable design and operation of cellulosic bioelectricity supply chain networks with life cycle economic, environmental, and social optimization. Industrial $\mathbb{E}$ Engineering Chemistry Research, 53(10):4008-4029, 2014.

A. Zamboni, F. Bezzo, and N. Shah. Spatially explicit static model for the strategic design of future bioethanol production systems. 2. multi-objective environmental optimization. Energy \& Fuels, 23(10): 5134-5143, 2009.

A. Zamboni, R. Murphy, J. Woods, F. Bezzo, and N. Shah. Biofuels carbon footprints: Whole-systems optimisation for ghg emissions reduction. Bioresource Technology, 102(16):7457-7465, 2011.

M. Zhang, B. Wiegmans, and L. Tavasszy. Optimization of multimodal networks including environmental costs: A model and findings for transport policy. Computers in Industry, 64(2):136-145, 2013.

\section{Further references}

P. Ahi and C. Searcy. An analysis of metrics used to measure performance in green and sustainable supply chains. Journal of Cleaner Production, 86:360-377, 2015.

E. Akçalı, S. Çetinkaya, and H. Üster. Network design for reverse and closed-loop supply chains: An annotated bibliography of models and solution approaches. Networks, 53(3):231-248, 2009.

N. Aras, T. Boyaci, and V. Verter. Designing the reverse logistics network. In M. Ferguson and G. Souza, editors, Closed Loop Supply Chains: New Developments to Improve the Sustainability of Business Practices, pages 67-98. Taylor and Francis, CRC Press, 2010.

M. O. Arioglu Salmona, A. Selam, and O. Vayvay. Sustainable supply chain management: a literature review. In ICOVACS 2010, International Conference on Value Chain Sustainability, 2010.

A. Ashby, M. Leat, and M. Hudson-Smith. Making connections: a review of supply chain management and sustainability literature. Supply Chain Management: An International Journal, 17(5):497-516, 2012.

C. Autry, T. Goldsby, J. Bell, M. Moon, C. Munson, M. Watson, S. Lewis, P. Cacioppi, and J. Jayaraman. The Definitive Guide to Modern Supply Chain Management (Collection). Pearson Education, 2013.

I. Awudu and J. Zhang. Uncertainties and sustainability concepts in biofuel supply chain management: A review. Renewable \&3 Sustainable Energy Reviews, 16(2):1359-1368, 2012.

A. Azapagic. Life cycle assessment and its application to process selection, design and optimisation. Chemical Engineering Journal, 73(1):1-21, 1999.

A. P. Barbosa-Póvoa. Process supply chains management - where are we? where to go next? Frontiers in Energy Research, 2(23), 2014.

B. M. Beamon. Supply chain design and analysis: Models and methods. International Journal of Production Economics, 55(3):281-294, 1998. 
C. Benoît-Norris. Data for social lca. The International Journal of Life Cycle Assessment, 19(2):261-265, 2014.

P. Beske, A. Land, and S. Seuring. Sustainable supply chain management practices and dynamic capabilities in the food industry: A critical analysis of the literature. International Journal of Production Economics, In Press, 2013.

N. Bostel, P. Dejax, and Z. Lu. Logistics Systems: Design and Optimization, chapter The Design, Planning and Optimization of Reverse Logistic Networks. Springer, 2005.

T. Boukherroub, J. Fondrevelle, A. Guinet, and A. Ruiz. Multi-criteria decision making for the supply chain design: A review with emphasis on sustainable supply chains. In Creative logistics for an uncertain world. Proceedings of the 4th International Conference on Information Systems, Logistics and Supply Chain, 2012.

M. Brandenburg, K. Govindan, J. Sarkis, and S. Seuring. Quantitative models for sustainable supply chain management: Developments and directions. European Journal of Operational Research, 233(2): 299-312, 2014.

I. Burton. Our Common Future - World Commission on Environment and Development. Environment, 29(5):25-29, 1987.

P. Castka and M. A. Balzarova. Iso 26000 and supply chains - on the diffusion of the social responsibility standard. International Journal of Production Economics, 111(2):274-286, 2008.

E. Chardine-Baumann and V. Botta-Genoulaz. A framework for sustainable performance assessment of supply chain management practices. Computers \& Industrial Engineering, 76(0):138-147, 2014.

L. Chen, J. Olhager, and O. Tang. Manufacturing facility location and sustainability: A literature review and research agenda. International Journal of Production Economics, 149(0):154-163, 2014. The Economics of Industrial Production.

S. Chopra and P. Meindl. Supply chain management. Pearson Prentice-Hall, 2. ed., internat. ed. edition, 2004.

M. S. Daskin, L. V. Snyder, and R. Berger. Facility location in supply chain design. In A. Langevin and D. Riopel, editors, Logistics Systems: Design and Optimization, pages 39-65. Springer US, 2005.

A. De Meyer, D. Cattrysse, J. Rasinmäki, and J. V. Orshoven. Methods to optimise the design and management of biomass-for-bioenergy supply chains: A review. Renewable and Sustainable Energy Reviews, 31(0):657-670, 2014.

R. Dekker, M. Fleischmann, K. Interfuth, and L. van Wassenhove, editors. Reverse logistics: quantitative models for closed loops supply chains. Springer-Verlag, 2004.

R. Dekker, J. Bloemhof, and I. Mallidis. Operations Research for green logistics - An overview of aspects, issues, contributions and challenges. European Journal of Operational Research, 219(3):671-679, 2012.

V. Dua and E. N. Pistikopoulos. An algorithm for the solution of multiparametric mixed integer linear programming problems. Annals of Operations Research, 99(1-4):123-139, 2000.

M. Fleischmann, J. Bloemhof-Ruwaard, R. Dekker, E. Laan, J. van Nunen, and L. Van Wassenhove. Quantitative models for reverse logistics: A review. European Journal of Operational Research, 103(1): $1-17,1997$. 
M. Goedkoop and R. Spriensma. The eco-indicator 99, a damage oriented method for life cycle impact assessment: Methodology report.(third edition). Technical report, PRé Consultants, 2000.

M. Goedkoop, R. Heijungs, M. Huijbregts, A. De Schryver, J. Struijs, and R. Van Zelm. ReCiPe 2008, a life cycle impact assessment method which comprises harmonised category indicators at the midpoint and the endpoint level. first edition. report i: Characterisation. Technical report, Rijksinstituut voor Volksgezondheid en Milieu, The Netherlands, 2009.

V. D. R. Guide and L. N. Van Wassenhove. Closed-loop supply chains: An introduction to the feature issue (part 1). Production and Operations Management, 15(3):345-350, 2006a.

V. D. R. Guide and L. N. Van Wassenhove. Closed-loop supply chains: An introduction to the feature issue (part 2). Production and Operations Management, 15(4):471-472, 2006b.

G. Guillén-Gosálbez. A novel MILP-based objective reduction method for multi-objective optimization: Application to environmental problems. Computers \& Chemical Engineering, 35(8):1469-1477, 2011.

S. Gupta and O. Palsule-Desai. Sustainable supply chain management: Review and research opportunities. IIMB Management Review, 23(4):234-245, 2011.

R. Hahn. Iso 26000 and the standardization of strategic management processes for sustainability and corporate social responsibility. Business Strategy and the Environment, 22(7):442-455, 2013.

S. L. Hakimi. Optimum locations of switching centers and the absolute centers and medians of a graph. Operations Research, 12(3):450-459, 1964.

E. Hassini, C. Surti, and C. Searcy. A literature review and a case study of sustainable supply chains with a focus on metrics. International Journal of Production Economics, 140(1):69-82, 2012.

I. Heckmann, T. Comes, and S. Nickel. A critical review on supply chain risk - definition, measure and modeling. Omega, 52(0):119-132, 2015.

M. Ilgin and S. Gupta. Environmentally conscious manufacturing and product recovery (ECMPRO): A review of the state of the art. Journal of Environmental Management, 91:563-591, 2010.

IPCC. Fourth Assessment Report: Climate Change 200\%: Working Group I Report: The Physical Science Basis. Geneva: IPCC, 2007.

ISO. Environmental management-life cycle assessment-principles and framework, 2006.

T. Johnsen, J. Miemczyk, and M. Macquet. Sustainable purchasing and supply management. Supply Chain Management, 17(5):478-496, 2012.

O. Jolliet, M. Margni, R. Charles, S. Humbert, J. Payet, G. Rebitzer, and R. Rosenbaum. Impact 2002+: A new life cycle impact assessment methodology. The International Journal of Life Cycle Assessment, 8(6):324-330, 2003.

A. Jorgensen. Social lca - a way ahead? The International Journal of Life Cycle Assessment, 18:296-299, 2013.

A. Jorgensen, A. Bocq, L. Nazarkina, and M. Hauschild. Methodologies for social life cycle assessment. The International Journal of Life Cycle Assessment, 13:96-103, 2008.

A. Kumar, V. Jain, and S. Kumar. A comprehensive environment friendly approach for supplier selection. Omega, 42(1):109-123, 2014. 
M. J. M. and V. B. G. Global supply chain design: A literature review and critique. Transportation Research Part E: Logistics and Transportation Review, 41(6):531 - 550, 2005.

S. M. Masoumik, S. H. Abdul-Rashid, E. Udoncy Olugu, and R. A. R. Ghazilla. Sustainable supply chain design: A configurational approach. The Scientific World Journal, 2014:16 pages, 2014.

E. Melachrinoudis. The location of undesirable facilities. In H. A. Eiselt and V. Marianov, editors, Foundations of Location Analysis, volume 155 of International Series in Operations Research 85 Management Science, pages 207-239. Springer US, 2011.

M. T. Melo, S. Nickel, and F. Saldanha-da Gama. Facility location and supply chain management - a review. European Journal of Operational Research, 196(2):401-412, 2009.

A. Messac, A. Ismail-Yahaya, and C. Mattson. The normalized normal constraint method for generating the pareto frontier. Structural and multidisciplinary optimization, 25(2):86-98, 2013.

J. Miemczyk, T. Johnsen, and M. Macquet. Sustainable purchasing and supply management: A review of definitions and measures at the dyad, chain and network levels of analysis. Supply Chain Management: An International Journal, 17(5):478-496, 2012.

G. Montibeller, V. Belton, F. Ackermann, and L. Ensslin. Reasoning maps for decision aid: an integrated approach for problem-structuring and multi-criteria evaluation. Journal of the Operations research Society, 59(5):575-589, 2008.

A. Nikolopoulou and M. Ierapetritou. Optimal design of sustainable chemical processes and supply chains: a review. Computers \& Chemical Engineering, 44:94-103, 2012.

OECD/IEA. $\mathrm{CO}_{2}$ emissions from fuel combustion 2012-highlights. Technical report, OECD/IEA, 2012. URL https://www.iea.org/co2highlights/co2highlights.pdf. (accessed March 28, 2014).

S. H. Owen and M. S. Daskin. Strategic facility location: a review. European Journal of Operational Research, 111(3):423-447, 1998.

R. Pati, R. Jans, and R. Tyagi. Green logistics network design: A critical review. In 24th Annual POMS conference, Denver, USA, 2013.

C. Pieragostini, M. C. Mussati, and P. Aguirre. On process optimization considering LCA methodology. Journal of Environmental Management, 96(1):43-54, 2012.

M. Pishvaee, R. Zanjirani Farahani, and W. Dullaert. A memetic algorithm for bi-objective integrated forward/reverse logistics network design. Computers \&3 Operations Research, 37(6):1100-1112, 2010.

S. Pokharel and A. Mutha. Perspectives in reverse logistics: A review. Resources, Conservation and Recycling, 53(4):175-182, 2009.

T. R. P. Ramos, M. I. Gomes, and A. P. Barbosa-Póvoa. Planning a sustainable reverse logistics system: Balancing costs with environmental and social concerns. Omega, 48:60-74, 2014.

T. L. Saaty. How to make a decision: The analytic hierarchy process. European Journal of Operational Research, 48(1):9-26, 1990.

G. Sahin and H. Süral. A review of hierarchical facility location models. Computers \& 8 Operations Research, 34(8):2310-2331, 2007.

J. Sarkis, Q. Zhu, and K. Lai. An organizational theoretic review of green supply chain management literature. International Journal of Production Economics, 130(1):1-15, 2011. 
N. Seman, N. Zakuan, A. Jusoh, and M. Arif. Green supply chain management: A review and research direction. International Journal of Managing Value and Supply Chains, 3(1), 2012.

S. Seuring. A review of modeling approaches for sustainable supply chain management. Decision Support Systems, 54(4):1513-1520, 2013.

S. Seuring and M. Müller. From a literature review to a conceptual framework for sustainable supply chain management. Journal of Cleaner Production, 16(15):1699-1710, 2008.

D. Simchi-Levi, P. Kaminsky, and E. Simchi-Levi, editors. Managing the Supply Chain: The Definitive Guide for the Business Professional. McGraw-Hill, 2004.

L. V. Snyder. Facility location under uncertainty: A review. IIE Transactions, 38:547-564, 2004.

M. Soysal, J. M. Bloemhof-Ruwaard, M. P. Meuwissen, and J. G. van der Vorst. A review on quantitative models for sustainable food logistics management. International Journal on Food System Dynamics, 3 (2):136-155, 2012 .

S. Srivastava. Green supply-chain management: A state-of-the-art literature review. International Journal Of Management Reviews, 9(1):53-80, 2007.

S. K. Srivastava. Network design for reverse logistics. Omega, 36(4):535-548, 2008.

S. A. Terouhid, R. Ries, and M. M. Fard. Towards sustainable facility location - a literature review. Journal of Sustainable Development, 5(7), 2012.

A. Weber and G. Peik. Über den Standort der Industrie. 1909.

L. A. Wright, S. Kemp, and I. Williams. Carbon footprinting: towards a universally accepted definition. Carbon Management, 2(1):61-72, 2011.

D. Yue, F. You, and S. W. Snyder. Biomass-to-bioenergy and biofuel supply chain optimization: Overview, key issues and challenges. Computers \& Chemical Engineering, 66(0):36-56, 2014 . Selected papers from ESCAPE-23 (European Symposium on Computer Aided Process Engineering - 23), 9-12 June 2013, Lappeenranta, Finland.

Y. Y. Yusuf, A. Gunasekaran, A. Musa, N. M. El-Berishy, T. Abubakar, and H. M. Ambursa. The UK oil and gas supply chains: An empirical analysis of adoption of sustainable measures and performance outcomes. International Journal of Production Economics, 146(2):501-514, 2013.

L. Zadeh. Fuzzy sets as a basis for a theory of possibility. Fuzzy Sets and Systems, 1:3-28, 1978.

S. Zailani, K. Jeyaraman, G. Vengadasan, and R. Premkumar. Sustainable supply chain management (SSCM) in Malaysia: A survey. International Journal of Production Economics, 140(1):330-340, 2012.

R. Zanjirani Farahani, S. Rezapour, T. Drezner, and S. Fallah. Competitive supply chain network design: An overview of classifications, models, solution techniques and applications. Omega, 45(0):92-118, 2014. 